\title{
Pharmacological interventions for the MATRICS cognitive domains in schizophrenia: what's the evidence?
}

\author{
Wilhelmina A. M. Vingerhoets ${ }^{1,2}$ *, Oswald J. N. Bloemen ${ }^{1}$, Geor Bakker ${ }^{1,2}$ and \\ Therese A. M. J. van Amelsvoort ${ }^{1}$
}

${ }^{1}$ Department of Psychiatry and Psychology, Maastricht University, Maastricht, Netherlands

2 Department of Nuclear Medicine, Academic Medical Centre, University of Amsterdam, Amsterdam, Netherlands

\section{Edited by:}

Stefan Borgwardt, University of

Basel, Switzerland

Reviewed by:

Alkomiet Hasan,

Ludwig-Maximilians-University

Munich, Germany

Rolf-Dieter Stieglitz, University of

Basel, Switzerland

${ }^{*}$ Correspondence:

Wilhelmina A. M. Vingerhoets,

Department of Psychiatry and

Psychology, Maastricht University,

Vijverdalseweg 1, Maastricht 6226

$N B$, Netherlands

e-mail: claudia.vingerhoets@

maastrichtuniversity.nl
Schizophrenia is a disabling, chronic psychiatric disorder with a prevalence rate of 0.5$1 \%$ in the general population. Symptoms include positive (e.g., delusions, hallucinations), negative (e.g., blunted affect, social withdrawal), as well as cognitive symptoms (e.g., memory and attention problems). Although $75-85 \%$ of patients with schizophrenia report cognitive impairments, the underlying neuropharmacological mechanisms are not well understood and currently no effective treatment is available for these impairments. This has led to the Measurement and Treatment Research to Improve Cognition in Schizophrenia (MATRICS) initiative, which established seven cognitive domains that are fundamentally impaired in schizophrenia. These domains include verbal learning and memory, visual learning and memory, working memory, attention and vigilance, processing speed, reasoning and problem solving, and social cognition. Recently, a growing number of studies have been conducted trying to identify the underlying neuropharmacological mechanisms of cognitive impairments in schizophrenia patients. Specific cognitive impairments seem to arise from different underlying neuropharmacological mechanisms. However, most review articles describe cognition in general and an overview of the mechanisms involved in these seven separate cognitive domains is currently lacking. Therefore, we reviewed the underlying neuropharmacological mechanisms focusing on the domains as established by the MATRICS initiative which are considered most crucial in schizophrenia.

Keywords: pharmacology, schizophrenia, cognition, MATRICS, neurotransmitters

\section{INTRODUCTION}

Schizophrenia is a disabling, chronic psychiatric disorder with a prevalence rate of $0.5-1 \%$ in the general population. Symptoms include positive and negative symptoms and disorganization. Approximately $75-85 \%$ of the schizophrenia patients report cognitive impairments as well (1). Although this aspect of schizophrenia was already described by Kraepelin nearly a century ago, cognitive impairments have long been under-identified as a symptom of schizophrenia and relatively little research has been conducted on this topic. Previous research showed that cognitive functioning is strongly associated with functional outcome in schizophrenia [e.g., skill acquisition in psychosocial rehabilitation treatment, demonstration of ability to solve simulated interpersonal problems, and community functioning $(2,3)]$. Cognitive impairments often precede the onset of other symptoms and persist after other psychotic symptoms have been effectively treated (4). Furthermore, severity of cognitive impairments is predictive of poorer medication compliance (5), treatment adherence (6), and increased tendency for relapse in first-episode patients (7). At present, no effective treatment is available as existing (antipsychotic) medication mainly targets positive symptoms and does not improve cognition. Although it is sometimes assumed by clinicians (possibly due to marketing) that atypical antipsychotics are superior to typical antipsychotics, results from recent studies contradict this theory. Presently available guidelines for treatment of schizophrenia, such as the NICE (8), PORT (9), and WFSBP (10) guidelines, indicate that there is no superiority of atypical antipsychotics on positive symptoms with the exception of clozapine, and instead state that use of antipsychotics should be evaluated based on their side effects. Since cognitive dysfunction is associated with functional outcome, development of an effective intervention strategy for these symptoms and corresponding guidelines is essential, as such guidelines are currently still lacking.

Lack of effective treatment strategies has over recent years led to an increase in studies investigating underlying neurobiological mechanisms of cognitive impairments and potential new pharmacological targets to enhance cognition in schizophrenia. Research has mainly focused on the role of neurotransmitters such as dopamine, serotonin, $\gamma$-aminobutyric acid (GABA), glutamate, and acetylcholine. Previous research indicated that specific cognitive impairments seem to arise from different underlying neurobiological mechanisms (11). For example, the prefrontal cortex (PFC) has been implicated in the executive functioning aspect of cognition (12) whereas the hippocampus has been linked to, e.g., episodic memory (13). This suggests that specific pharmacological agents could enhance domains of cognition differentially. Nonetheless, still little is known about the underlying neurobiology of cognition. Knowledge about these neurobiological mechanisms is highly necessary for development of new pharmacological intervention strategies. 
Table 1 | Pharmacological agents used and their main mechanism of action.

\begin{tabular}{|c|c|c|}
\hline $\begin{array}{l}\text { General } \\
\text { pharmacological } \\
\text { domain }\end{array}$ & $\begin{array}{l}\text { Pharmacological } \\
\text { agent }\end{array}$ & $\begin{array}{l}\text { Agents main mechanism } \\
\text { of action }\end{array}$ \\
\hline \multirow[t]{17}{*}{ Antipsychotics } & Haloperidol & $\mathrm{D}_{2}$ antagonist \\
\hline & Chlorprothixene & $\mathrm{D}_{2}$ antagonist \\
\hline & Perazine & $\mathrm{D}_{2}$ antagonist \\
\hline & Flupenthixol & $\mathrm{D}_{2}$ antagonist \\
\hline & Amisulpride & $\mathrm{D}_{2} / \mathrm{D}_{3}$ antagonist \\
\hline & Risperidone & $\mathrm{D}_{2}$ and $5-\mathrm{HT}_{2 \mathrm{a}}$ antagonist \\
\hline & Paliperidone & $\begin{array}{l}\mathrm{D}_{2} \text { and } 5-\mathrm{HT}_{2 \mathrm{a}} \text { antagonist (active } \\
\text { metabolite of risperidone) }\end{array}$ \\
\hline & Olanzapine & $\mathrm{D}_{2}$ and $5-\mathrm{HT}_{2 \mathrm{a}}$ antagonist \\
\hline & Loxapine & $\mathrm{D}_{2}$ and $5-\mathrm{HT}_{2 \mathrm{a}}$ antagonist \\
\hline & Sertindole & $\mathrm{D}_{2}$ and $5-\mathrm{HT}_{2 \mathrm{a}}$ antagonist \\
\hline & Ziprasidone & $\mathrm{D}_{2}$ and $5-\mathrm{HT}_{2 \mathrm{a}}$ antagonist \\
\hline & \multirow[t]{2}{*}{ Quetiapine } & $\mathrm{D}_{2}$ and $5-\mathrm{HT}_{2 \mathrm{a}}$ antagonist partial \\
\hline & & $5-\mathrm{HT}_{1 \mathrm{a}}$ agonist \\
\hline & Aripiprazole & $\begin{array}{l}5-\mathrm{HT}_{2 \mathrm{a}} \text { antagonist and partial } \mathrm{D}_{2} \\
\text { agonist and partial } 5-\mathrm{HT}_{1 \mathrm{a}} \text { agonist }\end{array}$ \\
\hline & Perospirone & $\begin{array}{l}\mathrm{D}_{2} \text { and } 5-\mathrm{HT}_{2 \mathrm{a}} \text { antagonist and } \\
5-\mathrm{HT}_{1 \mathrm{a}} \text { agonist }\end{array}$ \\
\hline & Clozapine & $\begin{array}{l}\mathrm{D}_{2}, \mathrm{D}_{4} \text {, and } 5-\mathrm{HT}_{2 \mathrm{a}} \text { antagonist } \\
\text { partial } 5-\mathrm{HT}_{1} \text { a agonist (metabolite } \\
\text { shows weak partial agonistic } \\
\text { effects on } \mathrm{D}_{2} \text { and } \mathrm{D}_{3} \text { ) }\end{array}$ \\
\hline & BL-1020 & $\begin{array}{l}\mathrm{D}_{2} \text { and } 5-\mathrm{HT}_{2 \mathrm{a}} \text { antagonist } \mathrm{GABA}_{A} \\
\text { agonist }\end{array}$ \\
\hline Dopaminergic & Dihydrexidine & $\mathrm{D}_{1}$ agonist \\
\hline \multirow[t]{5}{*}{ Serotonergic } & Ondansetron & $5-\mathrm{HT}_{3 \mathrm{a}}$ antagonist \\
\hline & Tandospirone & $5-\mathrm{HT}_{1 \mathrm{a}}$ agonist \\
\hline & Tropisetron & 5- $\mathrm{HT}_{3 а}$ antagonist \\
\hline & Fluvoxamine & $\begin{array}{l}\text { Reuptake inhibition and sigma-1 } \\
\text { receptor agonist }\end{array}$ \\
\hline & Citalopram & Reuptake inhibition \\
\hline \multirow[t]{5}{*}{ Cholinergic } & AZD3480 & nicotinic $\alpha_{4} \beta_{2}$ agonist \\
\hline & DMXB-A & Partial nicotinic $\alpha_{7}$ agonist \\
\hline & Donepezil & Acetylcholinesterase inhibition \\
\hline & Galantamine & Acetylcholinesterase inhibition \\
\hline & Rivastigmine & Acetylcholinesterase inhibition \\
\hline \multirow[t]{4}{*}{ Glutamatergic } & Minocycline & $\begin{array}{l}\text { (Mainly used as antibiotic) blocks } \\
\text { nitric oxide induced neurotoxicity }\end{array}$ \\
\hline & D-Cycloserine & NMDA partial agonist \\
\hline & Lamotrigine & Glutamate release regulation \\
\hline & Topiramate & AMPA/kainite antagonist \\
\hline \multirow[t]{3}{*}{ GABAergic } & MK-0777 & GABA $\alpha_{2} / \alpha_{3}$ agonist \\
\hline & Lorazepam & $\mathrm{GABA}_{\mathrm{A}}$ agonist \\
\hline & Flumazenil & $\mathrm{GABA}_{\mathrm{A}}$ antagonist \\
\hline Noradrenergic & Atomoxetine & Reuptake inhibition \\
\hline
\end{tabular}

(Continued)

\begin{tabular}{lll}
\hline $\begin{array}{l}\text { General } \\
\text { pharmacological } \\
\text { domain }\end{array}$ & $\begin{array}{l}\text { Pharmacological } \\
\text { agent }\end{array}$ & $\begin{array}{l}\text { Agents main mechanism } \\
\text { of action }\end{array}$ \\
\hline Stimulants & D-Amphetamine & $\begin{array}{l}\text { Dopamine/norepinephrine } \\
\text { releaser thus indirect dopamine } \\
\text { agonist } \\
\text { Unknown } \\
\text { Unknown }\end{array}$ \\
& Modafinil & $\begin{array}{l}\text { Glucocorticoid receptor } \\
\text { antagonist } \\
\text { Other domains }\end{array}$ \\
& Mifepristone & PDEhibition \\
\hline
\end{tabular}

To improve cognition research in schizophrenia the Measurement and Treatment to Improve Cognition in Schizophrenia (MATRICS) was developed. The MATRICS identified seven cognitive domains that are fundamentally impaired in schizophrenia: verbal learning and memory, visual learning and memory, working memory, attention and vigilance, processing speed, reasoning and problem solving, and social cognition (14). It was decided that cognition research in schizophrenia should mainly focus on these domains in order to identify the neurobiological mechanisms, ultimately to facilitate development of new pharmacological treatment strategies.

Although specific domains of cognition have been identified, most studies tend to describe cognition in general terms using a composite score. Currently, a review differentiating between separate MATRICS domains is lacking. Therefore, the aim of this review is to provide an outline of the underlying neuropharmacological mechanisms of each individual cognitive domain. We will focus on pharmacological intervention studies which used validated instruments to measure the effect on the MATRICS cognitive domains.

\section{METHODS}

\section{SEARCH STRATEGY}

A literature search was conducted in medical database PubMed. The following keywords were used: "pharmacology," "schizophrenia," and "Cognition." Subsequently, a separate search was conducted for each individual domain combining the keywords "pharmacology" and "schizophrenia" with the following keywords: "verbal learning," "verbal memory," "visual learning," "visual memory," "working memory," "attention," "vigilance," "processing speed," "reasoning," "problem solving," and "social cognition."

\section{INCLUSION AND EXCLUSION CRITERIA}

Papers that met the following inclusion criteria were included: (1) original research papers, both single challenge and clinical trials (full text available); (2) published in English; (3) use of a pharmacological intervention (pharmacological interventions used and their main mechanism of action are displayed in Table 1); (4) use of validated cognitive tests to measure one or more of the MATRICS domains; (5) subjects were patients with schizophrenia; 
and (6) were published between January 2000 and May 2013. Papers were excluded if: (1) only healthy subjects were included; (2) also schizoaffective disorders and other psychotic disorders were included; (3) cognitive domains were measured with nonvalidated tests; (4) cognitive domains other than the MATRICS domains were measured; and (5) only a composite score of cognition was reported.

\section{RESULTS}

In total, the search strategy yielded 938 articles of which 293 articles were found using the keywords "pharmacology," "cognition," and "schizophrenia." The separate searches yielded 158 articles for verbal learning and memory, 85 for visual learning and memory, 100 for working memory, 234 for attention and vigilance, 22 for processing speed, 17 for reasoning and problem solving, and 29 for social cognition. After final screening 44 articles were included for verbal learning and memory, 26 for visual learning and memory, 43 for working memory, 22 for attention and vigilance, 31 for processing speed, 30 for reasoning and problem solving, and 7 for social cognition. Study characteristics and specifics are shown in Table 2 (studies investigating antipsychotics) and Table 3 (studies investigating non-antipsychotic intervention strategies).

\section{VERBAL LEARNING AND MEMORY}

It has been proposed that impairments in verbal learning and memory are one of the most consistent cognitive deficits seen in schizophrenia (15) and is one of the most examined cognitive domains in these patients. A majority of the 44 included studies investigated the effects of typical and atypical antipsychotic medication on verbal learning and memory.

In the past, it was assumed that atypical antipsychotics are superior to typical antipsychotics in enhancing cognition in schizophrenia due to their affinity for both dopamine $\mathrm{D}_{2}$ receptors and serotonin $5-\mathrm{HT}_{2 \mathrm{~A}}$ receptors $(16,17)$. However large studies such as the Clinical Antipsychotic Trials of Intervention Effectiveness (CATIE) (18) and the European First Episode Schizophrenia Trial (EUFEST) (19) did not find differences between typical and atypical antipsychotics in cognitive enhancing effects. This theory was tested by Wagner et al. (16) who compared olanzapine, a dopamine $\mathrm{D}_{2}$, and serotonin $5-\mathrm{HT}_{2 \mathrm{~A}}$ antagonist, to amisulpride, a dopamine $\mathrm{D}_{2} / \mathrm{D}_{3}$ antagonist in 52 patients. No significant differences were found after 8 weeks between the two groups in terms verbal memory; both groups improved on verbal learning and memory tasks. Olanzapine was compared to risperidone and haloperidol by Purdon et al. (20). Although not significant after corrections for multiple comparisons, olanzapine was found to be superior to risperidone and haloperidol in enhancing verbal learning and memory.

The atypical antipsychotic ziprasidone was found to improve verbal learning and memory after 12 weeks of monotherapy (21). However, the study did not include a control group and practice effects were not adequately controlled for. Therefore the results have to be interpreted with caution. A study comparing the effects of risperidone and haloperidol on verbal memory found that performance on a verbal memory task remained essentially unchanged in both groups (22). Since the authors did not include a non-medicated schizophrenia group but included a healthy group as control this mainly provides evidence that there is no difference between risperidone and haloperidol. Nevertheless it suggests that both medications did not cause a clinically relevant enhancement of verbal memory. However, Harvey et al. (23) compared the effects of risperidone and quetiapine and found improvement in verbal memory in both treatment groups. The dropout rate of $57 \%$ in this trial was high which may have caused a selection bias. These results are not consistent with other findings. A small study with substantial methodological shortcomings by Purdon et al. (24) found no effect of haloperidol and quetiapine. Velligan et al. (25) also compared quetiapine to haloperidol and found that patients in the quetiapine group improved to a greater extent than the patients in the haloperidol group. However, these findings were not significant after correction for multiple comparisons. Moreover, Kivircik Akdede et al. (26) did not find improvement on a verbal learning and memory task after 8 weeks of quetiapine treatment.

Kim et al. (27) found that switching from oral atypical antipsychotics to depot risperidone led to significant improvement in verbal learning and memory. However, they also did not include a control group and did not correct for possible practice effects. Furthermore a high percentage of the patients dropped out in an early stage of the study which could have caused a bias in the sample. Despite these limitations, their results are supported by Suzuki and Gen (28) who also found an improvement in verbal learning and memory in patients treated with depot risperidone compared to patients who received haloperidol treatment (depot). However, the differences between these two treatments might be caused by the high rate of anticholinergic co-medication in the haloperidol group which is well known for its adverse effects on cognition (29). Additionally, improvement in verbal learning and memory was found by Surguladze et al. (30) with both depot risperidone and typical antipsychotics (depot). Performance did not significantly differ between the groups. However, they did not control for practice effects. Therefore improvement cannot reliably be attributed to medication effects. In addition, Kim et al. (31) found that compared to patients using risperidone, verbal memory improved more in patients using paliperidone extend release (ER), an active metabolite of risperidone with an extended delivery system that decreases fluctuations in serum drug concentrations.

Hence, the theory that atypical antipsychotic medications are superior to typical antipsychotics in enhancing verbal learning and memory is not supported by these findings. Nonetheless, some of the atypical antipsychotics, especially risperidone depot, have shown beneficial effects on this aspect of cognition.

Results regarding the effects of clozapine on verbal learning and memory are inconclusive. Three studies which investigated the effects of clozapine on verbal learning and memory were found. Purdon et al. (32) reported significant improvement in verbal learning and memory after treatment with clozapine. Their results were not replicated by Ertugrul et al. (33) and Sumiyoshi et al. (34) as both of these studies did not find improvement in verbal memory in clozapine-treated patients. This discrepancy in findings could be due to methodological differences such as different test batteries and trial duration. 


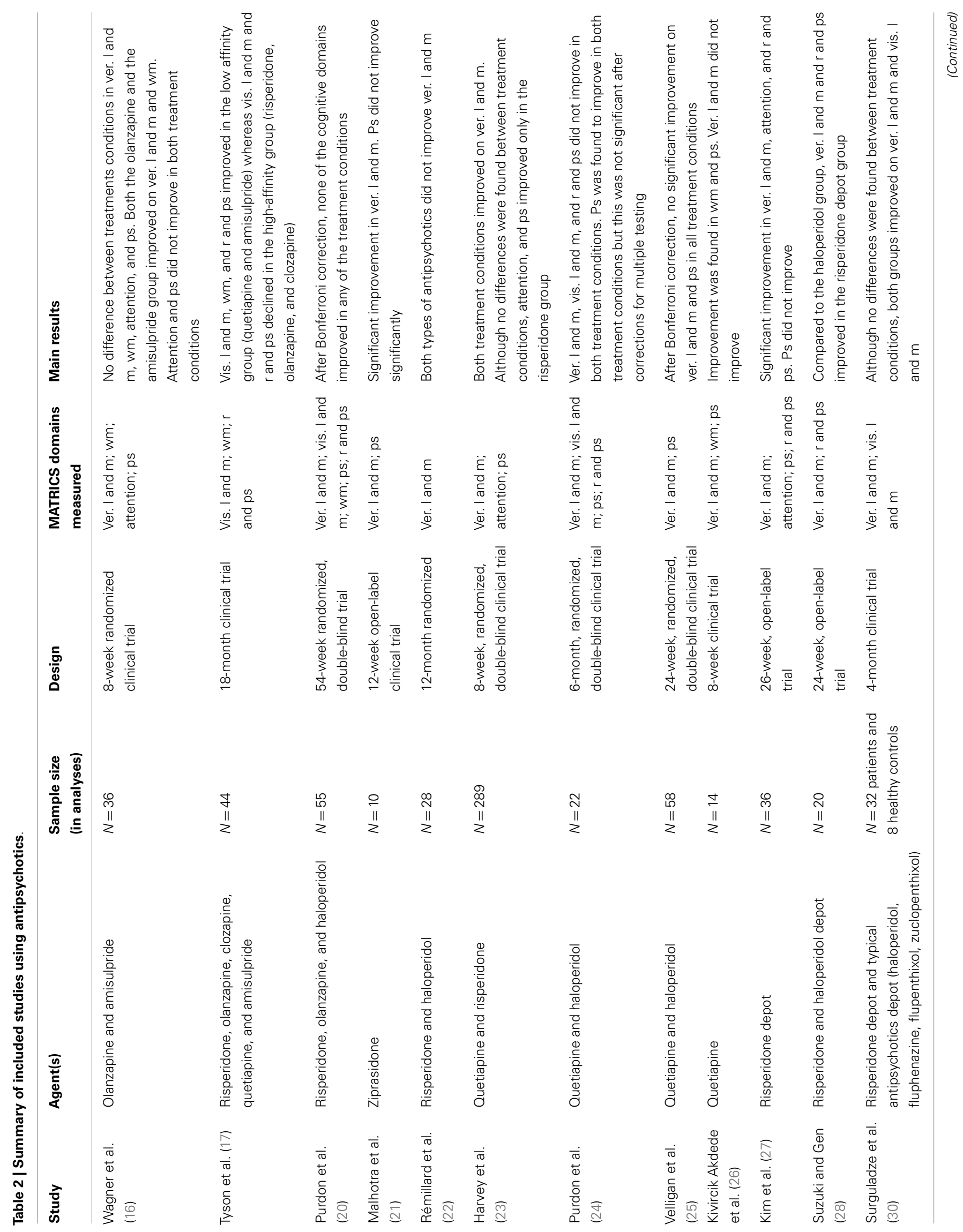




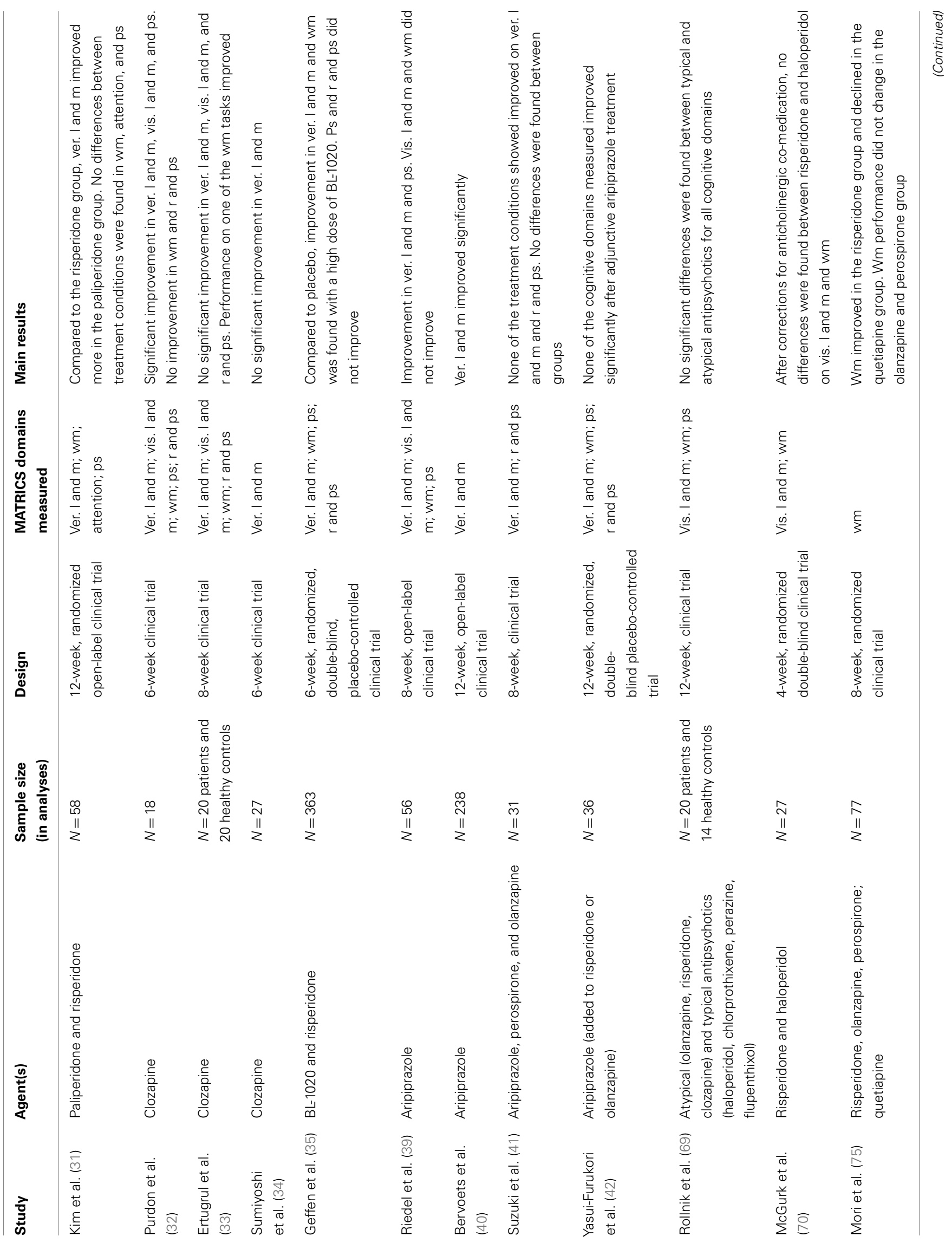



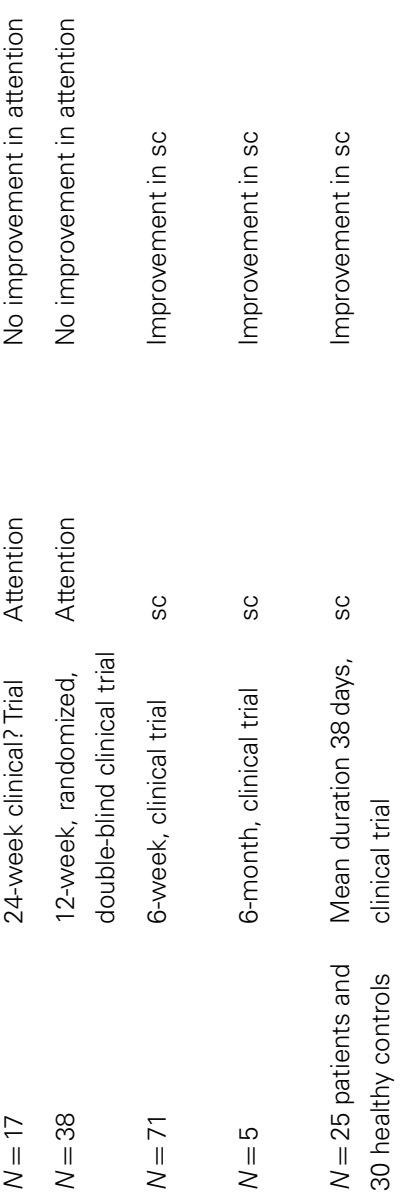

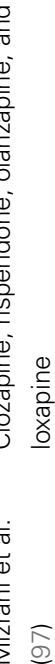

Moreover, the study by Purdon et al. (32) did not correct for possible practice effects and since they did not include a control group, improvement in verbal memory cannot be reliably attributed to the effects of clozapine. Thus, although results are inconclusive, at present no convincing evidence is available for the effectiveness of clozapine in enhancing verbal learning and memory in schizophrenia.

Geffen et al. (35) compared the effects of 10 and 20-30 mg of BL-1020, a new antipsychotic drug, to risperidone and placebo. BL-1020 is an antagonist for $\mathrm{D}_{2}$ en $5-\mathrm{HT}_{2 \mathrm{a}}$ receptors and agonist for $\mathrm{GABA}_{\mathrm{A}}$ receptors (35). Post-mortem studies have found altered GABAergic transmission in schizophrenia, predominantly in the PFC $(36,37)$. Treatment with $20-30 \mathrm{mg}$ BL-1020 was found to improve performance on a verbal learning memory task compared to placebo, whereas $10 \mathrm{mg}$ of BL-1020 and risperidone did not have enhancing effects compared to placebo. A substantial number of patients, especially in the risperidone group, received anticholinergics as well, which could have influenced the results.

Although the findings described above do not support the theory that blocking the $5-\mathrm{HT}_{2 \mathrm{~A}}$ receptors improves verbal learning and memory, a role for serotonin in this domain of cognition cannot be ruled out. Sumiyoshi et al. (38) found a significant improvement on verbal memory after adjunctive tandospirone (a $5-\mathrm{HT}_{1 \mathrm{a}}$ agonist) treatment compared to patients who did not receive adjunctive tandospirone. Riedel et al. (39) and Bervoets et al. (40) both found a significant improvement in verbal memory in patients treated with aripiprazole, an atypical antipsychotic drug with partial $\mathrm{D}_{2}$ agonistic and antagonistic and $5-\mathrm{HT}_{2 \mathrm{a}}$ antagonistic properties in addition to partial agonistic activity at the $5-\mathrm{HT}_{1 \mathrm{a}}$ receptors. However, this is contradicted by Suzuki et al. (41) who compared the effects of aripiprazole, olanzapine, and perospirone on verbal memory. None of the three conditions showed significant changes in verbal memory scores and no differences were found between the three treatment conditions. Moreover, aripiprazole added to atypical antipsychotics did not improve verbal learning and memory in a trial by Yasui-Furukori et al. (42). This discrepancy in findings could be due to practice effects in the studies of Riedel et al. (39) and Bervoets et al. (40), since both studies did not include a control group and did not correct for possible practice effects. Furthermore, different tasks were used which makes it difficult to directly compare the results.

The role of the serotonin $5-\mathrm{HT}_{3 \mathrm{a}}$ receptor in verbal learning and memory has been examined as well. Akhondzadeh et al. (43) and Levkovitz et al. (44) investigated the effects of ondansetron, a serotonin $5-\mathrm{HT}_{3 \mathrm{a}}$ receptor antagonist, added to respectively risperidone and clozapine treatment, and found no enhancing effects on verbal learning and memory. However, the sample size of both studies was small. In contrast to these results, Zhang et al. (45) did find improvement in verbal memory after add-on tropisetron (a $5-\mathrm{HT}_{3 \mathrm{a}}$ receptor antagonist and nicotinic $\alpha_{7}$ agonist) to risperidone treatment compared to placebo. This discrepancy in findings could be explained by the fact that the two studies used different pharmacological interventions. Both Akhondzadeh et al. (43) and Levkovitz et al. (44) administered ondansetron whereas Zhang et al. (45) used tropisetron. Since ondansetron has been found to have low affinity for the nicotinic $\alpha_{7}$ receptors (46), the positive effects of tropisetron on verbal learning and memory 


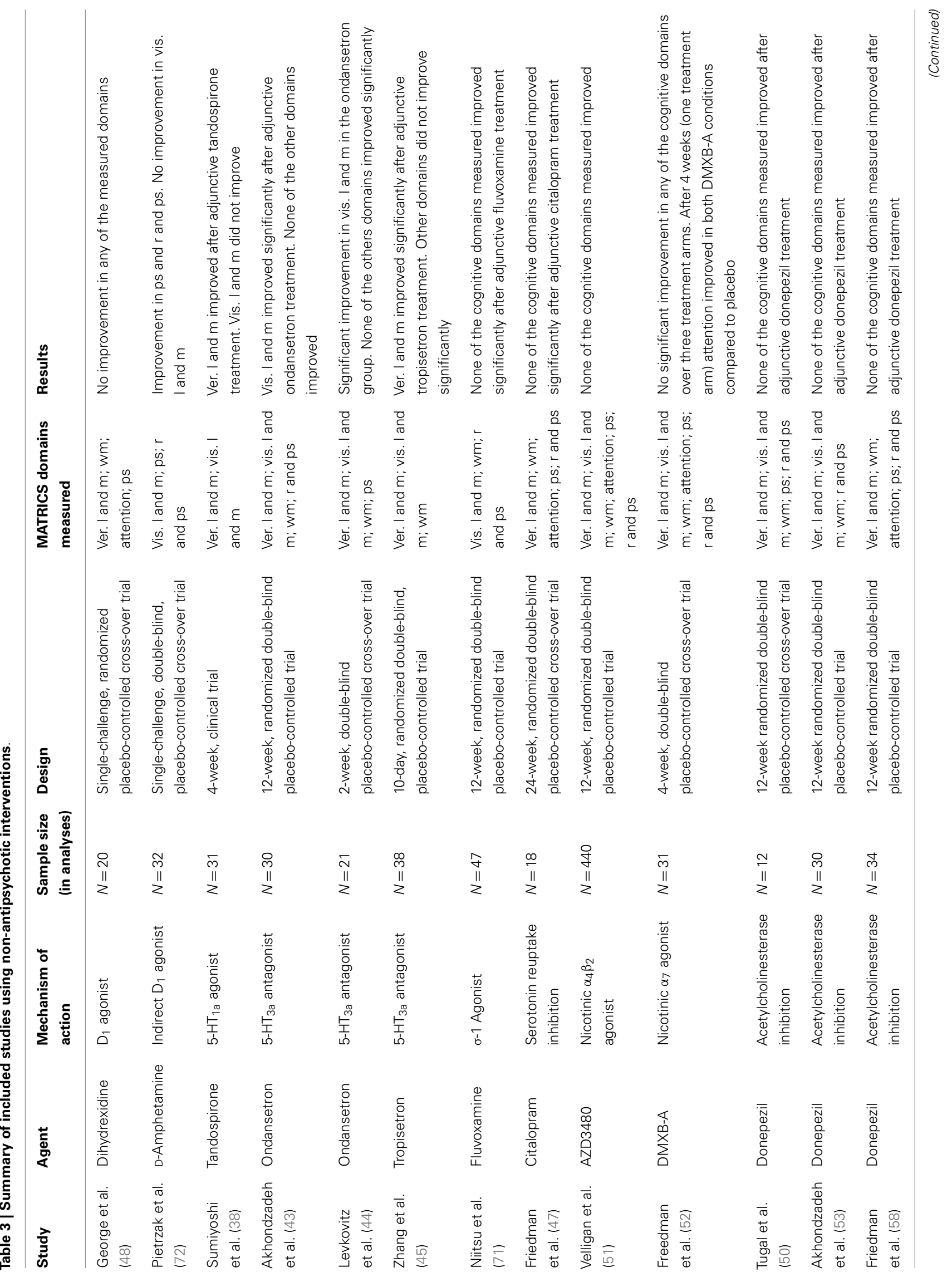




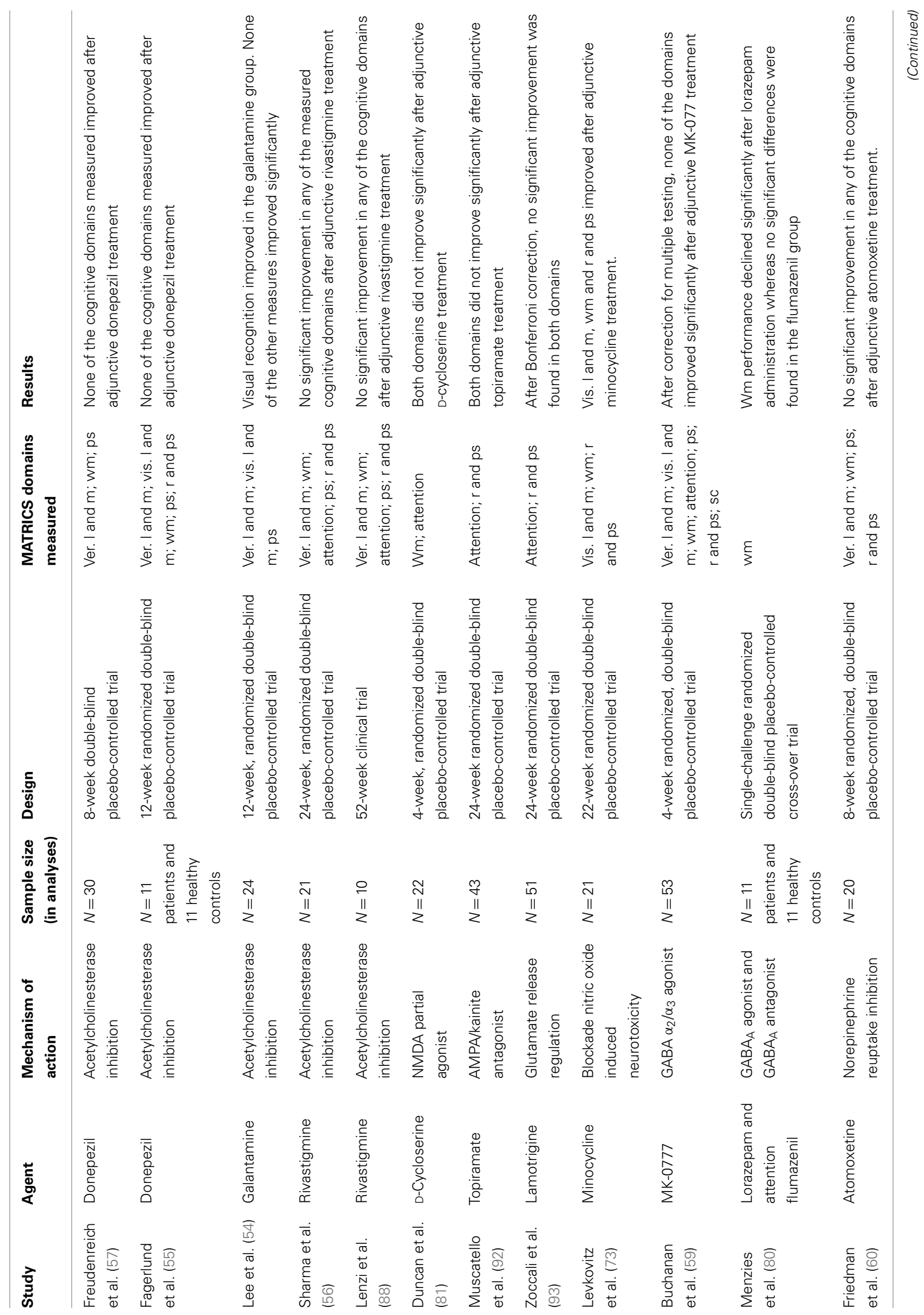




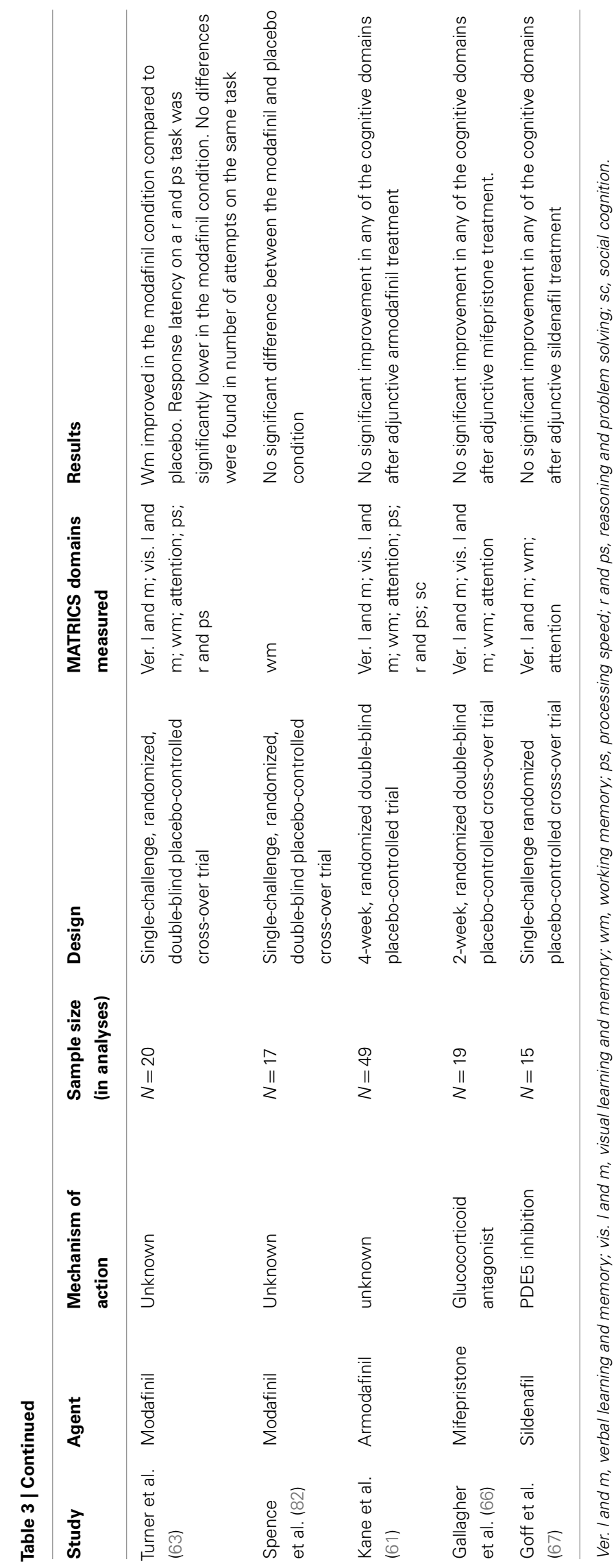

could be due to its nicotinic $\alpha_{7}$ agonistic properties rather than its antagonistic effects on the $5-\mathrm{HT}_{3 \mathrm{a}}$ receptors.

Effects of a selective serotonin reuptake inhibitor (SSRI) were examined by Friedman et al. (47) who added citalopram to treatment with atypical antipsychotics but found no improvement in verbal learning and memory.

Thus, although results are inconclusive there is preliminary evidence of positive effects of $5-\mathrm{HT}_{1 \mathrm{a}}$ agonists, but not $5-\mathrm{HT}_{3 \mathrm{a}}$ antagonists on verbal learning and memory in schizophrenia.

One study examined the effects of a dopamine $\mathrm{D}_{1}$ agonist on verbal learning and memory in schizophrenia. George et al. (48) administered dihydrexidine as a pharmacological challenge and found no effects of dihydrexidine on verbal learning and memory.

The role of the neurotransmitter acetylcholine in cognition has been widely investigated and established (36). Post-mortem, a correlation was found between cognitive impairment and decreased levels of brain choline acetyltransferase in schizophrenia (49). Post-mortem studies have shown changes in both muscarinic and nicotinic acetylcholine receptors in patients with schizophrenia (50). Velligan et al. (51) conducted a trial to assess the effects adjunctive therapy with the selective nicotinic $\alpha_{4} \beta_{2}$ receptor agonist AZD3480 on verbal learning and memory in patients but found no improvement. An important limitation of this study is that only patients who smoked were included. Therefore, the lack of effect could be due to desensitization of the nicotinic receptors caused by chronic tobacco use. However, Freedman et al. (52) also did not find an improvement in verbal learning and memory after administration of the partial nicotinic $\alpha_{7}$ agonist DMXB-A, added to antipsychotic treatment in patients, who abstained from nicotine at least 1 month prior to participation. Studies using acetylcholinesterase (enzyme that breaks down acetylcholine, thereby increasing acetylcholine levels) inhibitors (AChE-Is) as adjunctive therapy to antipsychotic medication also found no improvement on verbal learning and memory (53-58). These results suggest that acetylcholinesterase inhibitors do not effectively enhance verbal memory in patients with schizophrenia. However, all studies used a small sample size and one study included patients who were taking anticholinergic medication as well. This could have influenced the outcome of the study. Another important limitation is that none of these studies controlled for the effects of smoking. Hence, although there is theoretical evidence for a role of acetylcholine in cognition, various (possibly underpowered) intervention studies have not yielded positive results. Since Zhang et al. (45) found improvement in verbal learning and memory after adjunctive tropisetron treatment, it remains possible that enhancement of verbal learning and memory can be achieved with nicotinic $\alpha_{7}$ agonists while simultaneously blocking the $5-\mathrm{HT}_{3 \mathrm{a}}$ receptors.

The role of the neurotransmitters GABA and norepinephrine in verbal learning in memory has also been investigated. Buchanan et al. (59) found no improvement in verbal learning and memory with adjunctive MK-0777, a partial GABA $\alpha_{2} / \alpha_{3}$ agonist, therapy to antipsychotics. However, the authors argue that a lack of effect may be due to the fact that MK-0777 is a weak GABA $\alpha_{2} / \alpha_{3}$ agonist. A pilot study by Friedman et al. (60) found no effects of the norepinephrine reuptake inhibitor atomoxetine, on verbal memory when added to treatment with atypical antipsychotics. 
Hence, although positive effects were found with the antipsychotic BL-1020 with $\mathrm{GABA}_{\mathrm{A}}$ agonistic properties, the available studies were not able to detect positive effects of both a partial GABA $\alpha_{2} / \alpha_{3}$ agonist and a norepinephrine reuptake inhibitor on verbal learning and memory. Nonetheless, these results suggest that $\mathrm{GABA}_{\mathrm{A}}$ receptors may be a potential target for future studies in verbal learning and memory.

Effects of the psychostimulant armodafinil were investigated by Kane et al. (61). Armodafinil is a longer-lasting isomer of modafinil, which is an alertness-promoting medication with mechanisms of action different from those of amphetamine (62) and has been found to improve cognition in healthy subjects and adults with ADHD (63). However, the exact mechanisms of action are complex and not entirely understood (64). Armodafinil, added to atypical antipsychotics, did not enhance verbal learning and memory.

The effects of several other pharmacological interventions on verbal learning and memory in schizophrenia have been investigated. Six months of daily creatine administration added to antipsychotic treatment did not have beneficial effects on verbal learning and memory (65). Effects of adjunctive mifepristone, a glucocorticoid receptor (GR) antagonist, on verbal learning and memory was examined by Gallagher et al. (66). They found no improvement in this domain of cognition. Goff et al. (67) examined the effects of sildenafil, a phosphodiesterase 5 (PDE5) inhibitor used to treat erectile dysfunction, on verbal learning and memory. PDE5 inhibitors increase cyclic guanine monophosphate (cGMP) which is thought to modulate long-term potentiation. They found single dose of 50 and $100 \mathrm{mg}$ not to improve verbal learning and memory. On the other hand, Feifel et al. (15) found that patients who received intranasal oxytocin for 3 weeks performed better on a verbal learning and memory task. Additionally, Stone et al. (68) found that additional glucose administration in patients who were stable on clozapine, enhanced verbal learning and memory. All studies used a small sample and the dropout rate in the study by Feifel et al. (15) was $25 \%$. Moreover, the majority of the patients in the study of Stone et al. (68) received additional medication besides clozapine. Therefore the effect cannot be attributed to a unique interaction of clozapine and glucose.

To summarize, the proposed superior effect on verbal learning and memory of atypical to typical antipsychotics, is not supported by the available data and any effect does not result from blocking the $5-\mathrm{HT}_{2 \mathrm{a}}$ receptors. Despite the fact that multiple studies describe a role of acetylcholine in cognition, nicotinic receptor agonist and acetylcholinesterase inhibitors do not seem to effectively improve verbal learning and memory in schizophrenia. However, some positive results have been found with risperidone depot, possibly because of medication compliance. In addition, serotonin $5-\mathrm{HT}_{1 \mathrm{a}}$ receptors and $\mathrm{GABA}_{\mathrm{A}}$ receptors may be molecular targets for enhancing this aspect of cognition. Additionally, there is preliminary evidence that adjunctive oxytocin and glucose treatment may be beneficial in enhancing verbal learning and memory. However, results have to be interpreted with care as the available studies are mostly pilot studies which, although important in early stages of research, inherently suffer from methodological shortcomings.

\section{VISUAL LEARNING AND MEMORY}

Compared to verbal learning and memory, considerably less research has been conducted regarding visual learning and memory in schizophrenia. Results of studies that examined the effects of antipsychotic medication on visual learning and memory are, similar to verbal learning and memory, indecisive. Tyson et al. (17) compared the effects of atypical antipsychotic medication with high and low affinity for the $5-\mathrm{HT}_{2 \mathrm{a}}$ receptors on visual learning and memory. Patients treated with risperidone, olanzapine, and clozapine were assigned to the high-affinity group and patients using quetiapine and amisulpride were assigned to the low affinity group. Performance on visual memory tasks improved in patients in the low affinity group whereas performance in the high-affinity group declined. A limitation is that the authors did not correct for multiple testing. However, the effects were already present after 9 months of treatment and show a consistent pattern. Since performance declined in the high-affinity group, it is not likely that the improvement in the low affinity group is driven by practice effects. However, Rollnik et al. (69) found atypical antipsychotics (olanzapine, risperidone, or clozapine) to be superior to typical antipsychotics (haloperidol, chlorprothixene, perazine, or flupenthixol) in improving visual learning and after 3 weeks of treatment, although at the final assessment, this difference was no longer significant. Purdon et al. (20) compared the effects of olanzapine, risperidone, and haloperidol. After correction for multiple comparisons, no significant differences were found between the three treatment conditions; visual learning and memory did not improve in all three groups. As mentioned earlier, lack of effect could be caused by concomitant anticholinergic treatment and the small sample size.

Two studies compared the effects of haloperidol to respectively quetiapine (24) and risperidone (70). In both studies haloperidol and both quetiapine and risperidone were found not to enhance visual learning and memory. However, a substantial number of patients in both studies were treated with anticholinergics in addition to antipsychotics, which could have influenced the results. Surguladze et al. (30) found no differences in visual learning and memory between depot risperidone and a typical antipsychotic depot treatment, although performance in both groups improved. As discussed earlier, it cannot be ruled out that this improvement is caused by practice effects rather than the effects of medication.

Although results are inconclusive, clozapine does not seem to effectively enhance visual learning and memory. A study by Ertugrul et al. (33) did not find improvement with clozapine whereas Purdon et al. (32) found significant improvement on performance on one of three assessed visual memory subtests. However, this study has important limitations, which were described earlier.

Treatment with aripiprazole did not significantly improve visual learning and memory in the study by Riedel et al. (39). Tandospirone, which like aripiprazole has serotonin $5-\mathrm{HT}_{1 \mathrm{a}}$ agonistic properties, also did not significantly enhance visual learning and memory in the study of Sumiyoshi et al. (38). These findings suggest that stimulating the serotonin $5-\mathrm{HT}_{1 \mathrm{a}}$ receptors does not enhance visual learning and memory in schizophrenia. However, the serotonin $5-\mathrm{HT}_{3 \mathrm{a}}$ receptors may play a role in visual memory 
in schizophrenia. Both Akhondzadeh et al. (43) and Levkovitz et al. (44) found visual learning and memory to improve with adjunctive ondansetron treatment. Although both studies did not correct for multiple testing and possible practice effects, visual memory was the only aspect of the cognitive domains measured that improved in both studies. Adjunctive tropisetron treatment on the other hand did not enhance visual memory (45). As mentioned earlier, tropisetron is both a $5-\mathrm{HT}_{3 \mathrm{a}}$ antagonist and partial nicotinic $\alpha_{7}$ agonist whereas ondansetron has low affinity for the nicotinic $\alpha_{7}$ receptors (46). Hence, the 5-HT3a receptors may play a role in visual learning and memory. However, enhancement of this aspect of cognition may depend on blockade of nicotinic $\alpha_{7}$ receptors. The $5-\mathrm{HT}_{1 \mathrm{a}}$ receptor does not seem to be a promising target for enhancing visual learning and memory.

A preliminary study by Niitsu et al. (71) investigated the effect of the SSRI fluvoxamine, a sigma-1 receptor agonist, on cognition and found it not to enhance visual learning and memory. These preliminary results indicate sigma-1 receptor agonism does not enhance visual learning and memory in schizophrenia patients.

Studies investigating the role acetylcholine in visual learning and memory in schizophrenia have not yielded positive results. Selective nicotinic $\alpha_{4} \beta_{2}$ receptor agonist AZD3480 and partial nicotinic $\alpha_{7}$ agonist DMXB-A both did not enhance visual learning and memory when added to antipsychotic treatment (51, 52). As mentioned earlier, the lack of effect in the study of Velligan et al. (51) could be due to desensitization of the nicotinic receptors caused by chronic tobacco use since only smokers were included. Studies conducted with acetylcholinesterase inhibitors do not report positive results either. Although Lee et al. (54) found improvement on the recognition subtest of Rey Complex Figure Test (RCTF) with galantamine, the other aspects of the task did not improve. Studies using donepezil also did not find improvement in visual learning and memory $(50,53,55)$. Hence, both nicotinic receptor agonists and acetylcholinesterase inhibitors do not seem to effectively enhance visual learning and memory in schizophrenia.

Based on preliminary results of Buchanan et al. (59), GABA does not seem to enhance visual learning and memory in schizophrenia as they found no improvement with partial GABA $\alpha_{2} / \alpha_{3}$ agonist MK-0777. However, this is the only study investigating the role of GABA in visual learning and memory and MK-0777 is a weak GABA $\alpha_{2} / \alpha_{3}$ agonist.

The possible enhancing effect of psychostimulant drugs on visual learning and memory has been investigated in schizophrenia as well. A single dose of $\mathrm{D}$-amphetamine, an indirect dopamine $\mathrm{D}_{1}$ agonist, did not improve visual learning and memory (72). A single administration of modafinil did not significantly enhance visual memory either (63). In addition, adjunctive armodafinil treatment did not improve visual learning and memory (61). Hence, based on these findings D-amphetamine and modafinil do not seem to be promising intervention strategies for enhancing visual learning and memory.

Results of other pharmacological interventions on visual learning and memory are mixed. Gallagher et al. (66) found no improvement after adjunctive mifepristone (a GR antagonist) treatment. The effect of adjunctive creatine treatment was investigated by Kaptsan et al. (65) but they found it not to enhance visual learning and memory. Levkovitz et al. (73) investigated the effects of minocycline, a second generation tetracycline with antiinflammatory and antimicrobial effects. Minocycline modulates the glutamate pathway by blocking nitric oxide induced neurotoxicity. Hyperactivity of glutamatergic neurotransmission [possibly caused by hypofunction of $N$-methyl-D-aspartate (NMDA) receptors] has been found in schizophrenia (36). Stimulated by glutamate, the NMDA receptors activate production of nitric oxide. The authors found improvement on a spatial recognition memory task after minocycline administration, added to antipsychotic treatment. Task performance showed a decrease after 10 weeks, but compared to baseline, performance improved at the final assessment. The drop-out rate in this study was high (due to adverse events and non-adherence) and although it did not differ between the two treatment groups, this could have biased the results.

To summarize, results regarding visual learning and memory are inconclusive. At present, there is some evidence for a role of the serotonin $5-\mathrm{HT}_{3 \mathrm{a}}$ receptors in this cognitive domain. $5-\mathrm{HT}_{1 \mathrm{a}}$ and sigma-1 receptor agonist on the other hand, did not yield promising results. Additionally, minocycline was found to have positive effects on visual learning memory when added to antipsychotic treatment. Both typical and atypical antipsychotics do not seem to enhance visual learning and memory. Studies investigating nicotinic receptor agonist, acetylcholinesterase inhibitors, GABA $\alpha_{2} / \alpha_{3}$ agonist, psychostimulants, and GR antagonist did not yield positive results but are in need of replication as they were possibly underpowered. Overall, results need be interpreted with care as the described studies are often small pilot studies with inherent limitations.

\section{WORKING MEMORY}

Working memory refers to a system with limited capacity for temporary storage and manipulation of information, necessary for cognitive tasks (74), and has been the subject of many studies investigating cognition in schizophrenia. Most of these studies focused on the effects of antipsychotic medication on working memory.

Although results are inconclusive at present, both typical and atypical antipsychotics show little beneficial effects on working memory. Rollnik et al. (69) compared the effectiveness of typical and atypical antipsychotics and found no differences between the two groups. Quetiapine and amisulpride, which both have low affinity for the 5- $\mathrm{HT}_{2 \mathrm{a}}$ receptors, improved performance on a verbal working memory task compared to risperidone, olanzapine, and clozapine (high affinity for 5- $\mathrm{HT}_{2 \mathrm{a}}$ ) treatment (17). However, performance on a visual working memory tasks did not significantly improve in both groups. No differences were found in working memory performance between amisulpride and olanzapine by Wagner et al. (16). However, working memory performance did improve in both groups. Effects of olanzapine, risperidone, and haloperidol were compared by Purdon et al. (20). After correction for multiple comparisons, no significant differences were found between the three treatment conditions and working memory did not improve in any group. Mori et al. (75) examined the effects of switching from typical antipsychotics to olanzapine, quetiapine, risperidone, or perospirone on working memory and found improvement in working memory with risperidone, while 
working memory performance of the patients treated with quetiapine decreased. Working memory performance did not change in the olanzapine and perospirone group. It must be noted that the mean age in the sample was high (59.9 years) and correlated negatively with working memory scores. Therefore age related cognitive decline may have confounded these results. On the contrary, Kivircik Akdede et al. (26) found improvement on working memory with quetiapine. However, this study did not include a control group and did not correct for possible practice effects. Risperidone treatment was found to be superior to haloperidol in the study by McGurk et al. (70), but after correcting for anticholinergic co-medication, this effect was no longer significant. Working memory performance did not improve in both groups. Paliperidone treatment was not superior to risperidone treatment in enhancing working memory in the study by Kim et al. (31) and working memory did not improve in both groups.

Results regarding clozapine are inconclusive. Papageorgiou et al. (76) compared the effects of clozapine and olanzapine on working memory and found that working memory improved in both groups. No differences were found between the two treatment conditions. Ertugrul et al. (33) conducted two working memory tasks (Digit Span Test and the Auditory Consonant Trigram Test) and found that performance on the Digit Span test improved with clozapine treatment, whereas performance on the Auditory Consonant Trigram Test did not. Both studies did not correct for possible practice effects or multiple testing. These results are contradicted by Purdon et al. (32) who did not find improvement in working memory with clozapine treatment. This discrepancy in findings could be due to methodological shortcomings and differences such as different test batteries and trial duration.

Riedel et al. found that aripiprazole did not significantly enhance working memory (39). Aripiprazole also did not improve working memory when added to atypical antipsychotics (42). Adjunctive sertindole, an atypical antipsychotic with high affinity for the $\mathrm{D}_{2}$ and $5-\mathrm{HT}_{2 \mathrm{a}}$ receptors, did not improve working memory in patients treated with clozapine (77). Finally, working memory did improve after 20-30 mg of the novel antipsychotic BL-1020 (a dopamine antagonist with GABA agonistic properties) compared to placebo whereas $10 \mathrm{mg}$ BL-1020 and risperidone did not (35).

Hence, although results are preliminary and inconclusive, at present no convincing evidence is available for the effectiveness of both typical and atypical antipsychotics on working memory in schizophrenia. However, the antipsychotic BL-1020 was found to improve working memory, possibly through its $\mathrm{GABA}_{\mathrm{A}}$ agonistic properties.

Single administration of the dopamine $\mathrm{D}_{1}$ agonist dihydrexidine did not enhance working memory in a trial by George et al. (48). Given the small sample size and the fact that dihydrexidine was only administered a single time, beneficial effects of long term dihydrexidine administration on working memory cannot be ruled out.

Serotonin $5-\mathrm{HT}_{3 \mathrm{a}}$ receptors seem to be less important for working memory functioning. Both Akhondzadeh et al. (43) and Levkovitz et al. (44) found no improvement in working memory with adjunctive ondansetron (5- $\mathrm{HT}_{3 \mathrm{a}}$ antagonist) treatment.
Moreover, adjunctive tropisetron treatment also did not enhance working memory (45).

In addition, Niitsu et al. (71) found no improvement in working memory after adjunctive fluvoxamine treatment. Moreover, 12 weeks of adjunctive citalopram treatment did not enhance working memory (47). Hence, these results suggest that serotonin modulation pharmacological agents do not significantly enhance working memory in schizophrenia.

Both the selective nicotinic $\alpha_{4} \beta_{2}$ receptor agonist AZD3480 and the partial nicotinic $\alpha_{7}$ agonist DMXB-A did not enhance working memory performance $(51,52)$. Acetylcholinesterase inhibitors donepezil and rivastigmine did not enhance working memory either $(50,53-55,57,58,77)$. Jacobsen et al. (78) examined the effects of a single administration of nicotine [nicotinic acetylcholine receptor agonist (79)] on working memory in tobacco using patients and tobacco using healthy subjects. Although patients performed significantly worse on the N-back task compared to healthy controls, nicotine administration did improve performance on the two-back in patients while performance of the healthy controls declined. Thus, although the acetylcholinesterase inhibitors donepezil and rivastigmine and nicotinic receptor agonists do not show positive effects on working memory in schizophrenia, positive results were found with a single dose of nicotine administration. Therefore, a role of acetylcholine and nicotinic receptors in enhancing working memory cannot be ruled out.

Working memory did not improve in a study by Buchanan et al. (59) after 4 weeks of treatment with partial GABA $\alpha_{2} / \alpha_{3}$ agonist MK-0777. Menzies et al. (80) studied the effects of lorazepam, a $\mathrm{GABA}_{\mathrm{A}}$ receptor agonist, and flumazenil, a $\mathrm{GABA}_{\mathrm{A}}$ receptor antagonist, on working memory in patients and healthy subjects. Working memory performance declined after a single dose of lorazepam whereas performance did not change significantly after flumazenil. Thus, although results are inconclusive, there is some evidence that in $\mathrm{GABA}_{\mathrm{A}}$ agonists may lower working memory. However positive effects on working memory were found with an antipsychotic with additional $\mathrm{GABA}_{\mathrm{A}}$ agonistic properties.

Friedman et al. (60) found no effects of atomoxetine (norepinephrine reuptake inhibitor) on working memory in patients. A lack of effect could be due to insufficient power.

Glutamatergic pathways have been examined by Duncan et al. (81). They added $50 \mathrm{mg}$ of D-cycloserine, an antituberculous drug which, at low doses has agonistic properties at the NDMA receptors, to typical antipsychotics. After 4 weeks of treatment, working memory did not improve. However, these results need to be replicated before the role of NMDA receptors in working memory can be established.

Armodafinil, a longer-lasting isomer of modafinil, did not enhance performance on working memory task when added to atypical antipsychotics for 4 weeks (61). However, Turner et al. (63) found that a single dose of modafinil improved performance on a verbal working memory task compared to placebo. Performance on a spatial working memory task did not differ between modafinil condition and placebo condition. These results were not replicated by Spence et al. (82) who did not find differences in performance on a (verbal) working memory task after a single administration of modafinil compared to placebo. This discrepancy in findings could be due to differences in modafinil dose (200 
and $100 \mathrm{mg}$, respectively). Moreover, both studies used different tasks which make direct comparison of results difficult. Nonetheless, a single dose of modafinil might enhance working memory in schizophrenia patients, although recurrent treatment with a longer-lasting variant showed no effect.

Add-on intranasal oxytocin treatment did not improve working memory (15). Furthermore, adjunctive mifepristone (GR antagonist) treatment did not enhance working memory (66). Goff et al. (67) did not find improvement in working memory after both 50 and $100 \mathrm{mg}$ sildenafil administration. Furthermore, daily creatine administration added to antipsychotic treatment did not have beneficial effects on working memory either (65). Add-on minocycline treatment on the other hand, improved working memory in a study by Levkovitz et al. (73); the number of errors on a working memory task decreased significantly in the minocycline group whereas the number of errors in the placebo group increased. However, this study has some limitations which are described earlier. Thus, apart from minocycline, other lines of research did not identify possible new intervention strategies for working memory enhancement in schizophrenia.

To summarize, even though some positive results were found with minocycline, nicotine, and modafinil, the presently available studies did not identify promising molecular targets for enhancement of working memory in schizophrenia. GABA agonists have shown mixed results. Most of the studies examined the effects of antipsychotic treatment on working memory and only a limited number of studies used other pharmacological interventions, which makes it difficult to draw definite conclusions. More research needs to be conducted, especially on the potential role of GABA, norepinephrine, acetylcholine, glutamate, and psychostimulants.

\section{ATTENTION AND VIGILANCE}

The construct of attention refers to a core cognitive function that relates to the ability to select, filter, focus, and process different stimuli in the environment. Attention is closely related to working memory and executive functioning (83) and therefore, it is difficult to distinguish between these constructs. Because of the broad definition, impairment in virtually any task can be considered as impairment in attention (83). Therefore, in this review, we only included articles which used the Continuous Performance Test (CPT) to specifically measure attention as this test is recommended by the MATRICS (84).

Studies using antipsychotics to enhance attention report little beneficial effects. The theory that atypical antipsychotics are superior to typical antipsychotics in enhancing cognition was tested for attention as well. A trial comparing olanzapine to amisulpride did not find differences in effects on attention; attention did not significantly improve in both groups (16). Olanzapine did not enhance attention in a study by Molina et al. (85), who examined the effects of switching from typical antipsychotics or risperidone to olanzapine. Attention did not improve with olanzapine treatment.

The effects of risperidone on attention were compared to the effects of respectively haloperidol (86) and quetiapine (23). In the study of Liu et al. (86) no improvement was found in both the haloperidol and the risperidone group. Additionally, although no differences were found between the risperidone and quetiapine in the study by Harvey et al. (23), within group analyses showed significant improvement in attention in the risperidone group, whereas the quetiapine group did not improve. Kim et al. (27) reported improvement with depot risperidone. However, paliperidone did not improve attention (31). To summarize, both typical and atypical antipsychotics have shown little beneficial effects on attention in schizophrenia patients.

The possible role of dopamine and serotonin in attention has also been examined with intervention strategies other than antipsychotic treatment. George et al. (48) examined the effects of a full dopamine $\mathrm{D}_{1}$ agonist, dihydrexidine but found it not to enhance attention.

Studies using serotonin intervention strategies have not yielded positive results either. Golightly et al. (87) examined the role of serotonin in attention by using acute tryptophan, a precursor for serotonin, depletion. Depletion had no effect on performance on the CPT. Niitsu et al. (71) investigated the effect of adjunctive fluvoxamine treatment on attention and found no improvement in attention either. The effects of citalopram, added to treatment with atypical antipsychotics was examined by Friedman et al. (47). They found that adjunctive citalopram treatment did not enhance attention. Thus, although serotonin has been implicated in both verbal and visual memory, it does not seem to play a prominent role in attention.

Based on results of mostly preliminary studies, acetylcholine does not seem to play an important role in attention. Selective nicotinic $\alpha_{4} \beta_{2}$ receptor agonist AZD3480, did not enhance attention in a study by Velligan et al. (51). Nonetheless, Freedman et al. (52) found some beneficial effects of partial nicotinic $\alpha_{7}$ agonist DMXB-A on attention. In their cross-over study, patients were treated with 75, $150 \mathrm{mg}$ DMXB-A, and placebo. All treatment arms lasted 4 weeks, followed by a 1-week washout period. Over the course of the trial, attention improved in all treatment groups. The authors suggested that possible practice effects had obscured the potential effect of treatment, and therefore also examined the scores after the first 4 weeks of treatment. They found that attention improved with both doses of DMXBA compared to the placebo. Two types of acetylcholinesterase inhibitors, rivastigmine, and donepezil, did not enhance attention in schizophrenia $(56,58,88)$. On the other hand, a single nicotine administration improved attention in schizophrenia patients but not in healthy controls (89). Thus, despite negative results with acetylcholinesterase inhibitors, some promising results have been obtained with nicotine and a partial nicotinic $\alpha_{7}$ agonist. These preliminary results suggest that the nicotinic receptors are a potential target for enhancement of attention in schizophrenia.

Partial GABA $\alpha_{2} / \alpha_{3}$ agonist MK-0777 did not enhance attention when added to antipsychotic treatment (59). However, as mentioned earlier, MK-0777 is a weak GABA $\alpha_{2} / \alpha_{3}$ agonist and this is the only study investigating the potential role of GABA in attention in schizophrenia. Therefore, these results need to be replicated using specific and more potent GABA modulatory agents.

Other lines of research have not yielded positive results. The psychostimulant drug armodafinil did not enhance attention (61). Furthermore, adjunctive mifepristone (GR antagonist) therapy did not improve attention (66). Duncan et al. (81) found no 
improvement in attention with adjunctive $\mathrm{D}$-cycloserine treatment. Also, sildenafil (PDE5 inhibitor) did not enhance attention in schizophrenia in a trial by Goff et al. (67). Stone et al. (68) compared the effects of single administration of glucose to placebo in clozapine-treated patients and found attention to be significantly worse in the glucose condition. Thus, several other lines of research did not identify potential new intervention strategies enhancement of attention in schizophrenia.

To summarize, at present only a few pharmacological intervention strategies have been effective in enhancing attention in schizophrenia. Although results are not consistent, positive results have been found with both oral and depot risperidone treatment. Furthermore, a partial nicotinic $\alpha_{7}$ agonist, and a single administration of nicotine did improve attention in schizophrenia, suggesting a role for acetylcholine and nicotinic receptors in attention. Overall, results need to be considered preliminary and more research needs to be conducted to replicate these findings as these studies have some important limitations.

\section{PROCESSING SPEED}

Processing speed is considered a core cognitive function and refers to the speed at which the brain processes information. It can be measured as the number of correct responses during a task within a given amount of time (90).

As for other domains of cognition, a majority of the studies examined the effects of antipsychotic medication on processing speed. The theory that atypical antipsychotics are superior to typical antipsychotics in improving cognition in patients was tested for processing speed as well. A study comparing amisulpride with olanzapine found that processing speed did not improve in both groups (16). Moreover, performance on a processing speed task did not differ between patients treated with different typical antipsychotics and atypical antipsychotics and performance did not improve in both groups (69). Purdon et al. (20) compared the effects of olanzapine, risperidone, and haloperidol on processing speed. After correction for multiple comparisons, no significant differences were found between the three treatment conditions and processing speed did not improve in any of the groups. Thus, atypical antipsychotics do not appear to be superior to typical antipsychotics. Furthermore, no beneficial effects of the atypical antipsychotic ziprasidone were found on processing speed (21). Anticholinergics were allowed during the trial which might have influenced the results. Risperidone depot treatment did not enhance processing speed in the study by Kim et al. (27). Moreover, paliperidone ER was not found to be superior to risperidone (31). Unfortunately, within group comparisons were not reported. However, although no significant differences were found between two treatment groups, risperidone was found to improve processing speed whereas quetiapine did not in a study comparing these two antipsychotics (23). Contrary to those results, quetiapine was found to enhance processing speed in a trial by Kivircik Akdede et al. (26). As described earlier, this study did not include a control group and did not correct for possible practice effects. These results were not replicated by Purdon et al. (24). Although processing speed improved in both the quetiapine and haloperidol group, these results were not significant after correcting for multiple comparisons. Velligan et al. (25) compared the effectiveness on processing speed between quetiapine and haloperidol treatment. They found no differences between the two treatment groups. Purdon et al. (32) found that processing speed improved with clozapine treatment. However, this improvement cannot reliably be attributed to the effects of clozapine as the study did not include a control group en they did not correct for possible practice effects. Beneficial effects of aripiprazole on processing speed were found by Riedel et al. (39). YasuiFurukori et al. (42) found no improvement in processing speed with adjunctive aripiprazole treatment to olanzapine or risperidone. Furthermore, a new antipsychotic with $\mathrm{GABA}_{\mathrm{A}}$ receptor agonistic properties in addition to dopamine $\mathrm{D}_{2}$ and serotonin $5-\mathrm{HT}_{2 \mathrm{a}}$ receptor blockade (BL-1020) did not improve processing speed (35).

To summarize, both typical and atypical antipsychotics do not seem to effectively enhance processing speed in schizophrenia patients. Although some studies reported positive effects of clozapine, quetiapine, and risperidone, these results should be interpreted with care as these studies have important limitations.

Studies examining the role of serotonin in processing speed did not yield positive results. Adjunctive ondansetron $\left(5-\mathrm{HT}_{3 \mathrm{a}}\right.$ receptor antagonist) therapy to antipsychotic medication did not enhance processing speed in a study by Levkovitz et al. (44). Adding citalopram to atypical antipsychotic treatment also did not enhance processing speed in the study by Friedman et al. (47). In addition, tryptophan depletion did not affect processing speed in the study by Golightly et al. (87). Thus, the available studies do not provide evidence for a prominent role of serotonin in processing speed in schizophrenia. However, all studies used small samples and the study of Golightly et al. (87) allowed concomitant anticholinergics which could have influenced the results.

Studies using acetylcholine related intervention strategies did not yield positive results either. Both the selective nicotinic $\alpha_{4} \beta_{2}$ receptor agonist $\mathrm{AZD} 3480$ and the partial nicotinic $\alpha_{7}$ agonist DMXB-A did not enhance processing speed (51, 52). Moreover, three types of acetylcholinesterase inhibitors, donepezil, galantamine, and rivastigmine, did not improve processing speed (50, 54-58). Thus, although the role of acetylcholine in memory and attention has been well established, it does not seem to be a potential target in enhancing processing speed in schizophrenia. However, these studies have limitations such as small sample sizes.

Effects of GABA and norepinephrine on processing speed were also examined. Processing speed did not improve after adjunctive treatment with partial $\alpha_{2} / \alpha_{3}$ agonist MK-0777 (59). As mentioned earlier, BL-1020 (antipsychotic with $\mathrm{GABA}_{\mathrm{A}}$ agonistic properties) enhanced antipsychotic also did not enhance processing speed (35). In the pilot study of Friedman et al. (60), processing speed did not improve after adjunctive treatment with the norepinephrine reuptake inhibitor atomoxetine. Thus, norepinephrine and GABA $\alpha_{2} / \alpha_{3}$ receptors do not seem to play an important role in processing speed in schizophrenia as the available studies were not able to detect positive effects. However, lack of effect could be due to the small sample size of both studies.

Processing speed did increase after a single dose of $\mathrm{D}$ amphetamine in the study of Pietrzak et al. (72). Adjunctive armodafinil treatment had no beneficial effects on processing speed in the study by Kane et al. (61). Hence, since D-amphetamine 
is an indirect dopamine $D_{1}$ agonist, dopamine $D_{1}$ receptors could be a possible target for enhancing processing speed in schizophrenia although the study by Pietrzak et al. (72) needs replication.

Lastly, there are some studies of agents that have no direct (known) effect on neurotransmission. Processing speed did not improve after single dose of 50 and $100 \mathrm{mg}$ sildenafil (a PDE5 inhibitor commonly used for erectile dysfunction) in the crossover trial by Goff et al. (67). Furthermore, adjunctive dehydroepiandrosterone (DHEA) therapy, a corticosteroid that serves as a precursor for both androgenic and estrogenic steroids, did not enhance processing speed (91). Thus, other lines of research did not identify promising intervention strategies for enhancement of processing speed in schizophrenia.

To summarize, at present no convincing evidence exist for the effectiveness of both typical and atypical antipsychotics on processing speed in schizophrenia. Although, positive results were found with quetiapine, risperidone, clozapine, and aripiprazole, these studies have important limitations and therefore the effects cannot be reliably attributed to the effects of the medication. One positive result was found with single dose $\mathrm{D}$-amphetamine, suggesting a potential role of dopamine $\mathrm{D}_{1}$ receptors in processing speed. Studies investigating $5-\mathrm{HT}_{3 \mathrm{a}}$ receptor antagonist, SSRI, nicotinic receptor agonist, acetylcholinesterase inhibitors, a GABA $\alpha_{2} / \alpha_{3}$ agonist, and a norepinephrine reuptake inhibitor did not find clinically relevant improvement in processing speed but are in need for replication as the described studies used small samples and were possibly underpowered.

\section{REASONING AND PROBLEM SOLVING}

We found 30 studies that measured reasoning and problem solving after a pharmacological intervention. Reasoning and problem solving is considered an aspect of executive functioning. As for the other cognitive domains, a relatively large number of studies investigated the effects of antipsychotics on reasoning and problem solving.

Tyson et al. (17) compared antipsychotics with low affinity for $5-\mathrm{HT}_{2 \mathrm{a}}$ receptors to antipsychotics with high affinity for these receptors. Response latency on a reasoning and problem solving task decreased in the low affinity group, whereas latency increased in the high-affinity group. The authors did not correct for multiple comparisons. Since response latency increased in the high-affinity group, it is not likely that the improvement in the low affinity group is (only) driven by practice effects. Purdon et al. (20) compared the effects of olanzapine, risperidone, and haloperidol and found that olanzapine was superior in enhancing reasoning and problem solving. However, after correcting for multiple comparisons, none of the medications improved reasoning and problem solving. On the contrary, both Kim et al. (27) and Suzuki and Gen (28) found improvement in performance on a reasoning and problem solving task. However, Kim et al. (27) did not include a control group and did not correct for possible practice effects. Therefore, improvement cannot be reliably attributed to the effects of medication. Moreover, in the study of Suzuki and Gen (28) a high percentage of the patients in the haloperidol group was using concomitant anticholinergics whereas in the risperidone group anticholinergics were tapered during the first weeks of the trial.
Therefore improvement in this group could be due to effects of diminishing anticholinergics.

Purdon et al. (24) investigated the effects of haloperidol and quetiapine and found that reasoning and problem solving did not improve in both groups. Olanzapine, perospirone, and aripiprazole did not improve reasoning and problem solving either (41). Moreover, adding aripiprazole to atypical antipsychotics also did not yield positive results (42). Furthermore, no improvement was found with clozapine by Ertugrul et al. (33) and Purdon et al. (32). Nielsen et al. (77) added sertindole to clozapine but found no improvement in reasoning and problem solving either. Finally, the new antipsychotic with GABA agonistic properties BL-1020 also did not improve reasoning and problem solving (35). Hence, although positive results were found with risperidone depot, both typical and atypical antipsychotics have shown little clinically relevant effects on reasoning and problem solving.

Serotonergic intervention strategies have not yielded positive results. Adjunctive ondansetron $\left(5-\mathrm{HT}_{3}\right.$ antagonist) treatment had no beneficial effects on reasoning and problem solving (43). Fluvoxamine and citalopram both did not enhance reasoning and problem solving either $(47,71)$. On the contrary, Golightly et al. (87) found that patients who underwent tryptophan depletion during the first session performed significantly worse on the Wisconsin Card Sorting Test (WCST) compared to placebo. However, this effect was not present during the second session. The WCST requires subjects to sort cards by a certain parameter. The subject is not told which parameter. The sorting principle changes after 10 correct responses in a row. Thus subjects have to acquire a certain strategy to sort the cards. The authors concluded that tryptophan depletion only affected strategy acquisition and that once this is learned; tryptophan depletion did not interfere with application of this strategy. Thus, based on the results described above, 5- $\mathrm{HT}_{3 \mathrm{a}}$ antagonist and SSRI's did not effectively enhance reasoning and problem solving. However, a role for serotonin in this aspect of cognition cannot be ruled out since tryptophan depletion did interfere with strategy acquisition.

Partial nicotinic $\alpha_{7}$ agonist DMXB-A had no enhancing effects on reasoning and problem solving in the study by Freedman et al. (52). In addition, studies investigating the effects of the acetylcholinesterase inhibitors donepezil and rivastigmine did not find improvement in performance on a reasoning and problem solving task either $(50,53,56,58)$. Hence, based on these results, nicotinic $\alpha_{7}$ agonists and acetylcholinesterase inhibitors do not appear to significantly enhance reasoning and problem solving in schizophrenia.

In line with the results of Geffen et al. (35) described earlier, no positive results were obtained with other GABAergic interventions strategies. Adjunctive therapy with partial GABA $\alpha_{2} / \alpha_{3}$ agonist MK-0777 did not enhance reasoning and problem solving abilities in the study by Buchanan et al. (59). In addition, adjunctive topiramate (an antiepileptic drug which potentiates GABAergic transmission probably through its AMPA/kainite receptor antagonistic properties) treatment did not enhance reasoning and problem solving either (92). Zoccali et al. (93) examined the effects of adjunctive lamotrigine, an anticonvulsant drug which reduces excessive glutamate release in the brain via inhibition of 
voltage-gated sodium and calcium channels (94). Reasoning and problem solving did not improve.

The potential role of norepinephrine in reasoning and problem solving in schizophrenia was examined in a pilot study by Friedman et al. (60) by adding atomoxetine to antipsychotic treatment. They found no improvement in this aspect of cognition.

In conclusion, the available evidence suggests that modulation of GABA and glutamate transmission and norepinephrine reuptake inhibition does not have enhancing effects on reasoning and problem solving abilities in schizophrenia.

Some positive results have been found with psychostimulant drugs. Compared to placebo, performance on a reasoning and problem solving task improved after a single dose of $\mathrm{D}^{-}$ amphetamine [indirect dopamine $\mathrm{D}_{1}$ agonist, (72)]. Contrary to these results, Turner et al. (63) found that, compared to placebo, response latency on the Tower of London task was significantly lower after modafinil administration. The number of attempts to obtain the correct solution did not differ between the two groups. Armodafinil, the longer-lasting isomer of modafinil, did not affect reasoning and problem solving abilities (61). Thus, although armodafinil and modafinil did not enhance reasoning and problem solving, D-amphetamine did improve this aspect of cognition. This suggests that dopamine $\mathrm{D}_{1}$ agonists are a potential area of research for further study of reasoning and problem solving in schizophrenia.

Pharmacological intervention strategies that do not directly influence neurotransmission were also investigated. Levkovitz et al. (73) found that reasoning and problem solving abilities improved after add-on minocycline treatment whereas performance in the placebo group did not change. Both creatine and glucose had no enhancing effects on reasoning and problem solving; daily creatine administration in addition to antipsychotic treatment did not have beneficial effects on working memory in the study by Kaptsan et al. (65). Stone et al. (68) found no improvement in reasoning and problem solving after a single dose of glucose. Hence, despite of the study's limitations, minocycline's putative ability to improve reasoning and problem solving abilities should be studied further.

In conclusion, although positive results were found with depot risperidone treatment in studies with important limitations, antipsychotics do not seem to effectively improve reasoning and problem solving in schizophrenia. The available studies did not show enhancing effects of the neurotransmitters serotonin, acetylcholine, GABA, or norepinephrine on reasoning and problem solving. However, dopamine $\mathrm{D}_{1}$ agonists may have potential in this cognitive domain since one positive result was found with a single dose D-amphetamine. Finally, minocycline had enhancing effects on reasoning and problem solving abilities. However, this study has important limitations. Therefore these results are in need for replication.

\section{SOCIAL COGNITION}

In general terms, social cognition refers to the cognitive processes used to decode and encode the social world (95). Of all the MATRICS cognitive domains, social cognition has received the least attention in research. This is probably due to the fact that it is a relatively new area in schizophrenia research (96) and that the boundaries of this domain are not entirely clear (96). Final screening yielded no more than seven articles on social cognition and pharmacology using validated outcome measures.

A study by Mizrahi et al. (97) examined the effects of antipsychotic treatment on social cognition in schizophrenia. They investigated the effects of clozapine, risperidone, olanzapine, and loxapine on Theory of Mind (TOM). TOM is an aspect of social cognition which refers to the ability to understand intentions of others and to recognize that their actions are guided by beliefs about the world (97). They found that TOM improved after 2 weeks of medication use and continued to improve during the rest of the trial. Unfortunately, the authors did not differentiate between the four different antipsychotics. However, all four types of medication have high affinity for dopamine $\mathrm{D}_{2}$ receptors as well as the $5-\mathrm{HT}_{2 \mathrm{a}}$ receptors $(98,99)$. These results are in line with the results of Sumiyoshi et al. (100) who found that perospirone treatment improved performance on a social cognition task. Nonetheless, both studies did not include a control group and used small samples. Hence, given the longitudinal design of this study, natural progression and practice effects cannot be excluded. Additionally, the high drop-out rate in the study of Sumiyoshi et al. (100) could have led to a bias in the sample. Behere et al. (101) found that performance on an emotion recognition task improved after risperidone treatment. However, it must be noted that they did not include a control group and that time of follow-up assessment was not equal for all patients. Opposed to these results, the study by Harvey et al. (23) discussed earlier did not find improvement in performance on an emotional recognition task in patients treated with either quetiapine or risperidone.

Hence, these results imply preliminary evidence that dopamine and serotonin are important for TOM related aspects of social cognition but not for emotion recognition.

The possible role of GABA in social cognition was investigated by Buchanan et al. (59). They found no improvement with the partial GABA $\alpha_{2} / \alpha_{3}$ agonist MK-0777 when added to antipsychotic treatment. The psychostimulant armodafinil also did not improve social cognition (61). Hence, GABA $\alpha_{2} / \alpha_{3}$ receptors are not prime candidates for enhancing social cognition in schizophrenia.

Another line of research focused on the role of oxytocin in social cognition. This neuropeptide is known for its role in positive social behavior (102). Pedersen et al. (103) found that intranasal oxytocin administration improved social cognition. This implicates a role for oxytocin in social cognition. Since previous research showed that plasma oxytocin levels are lower in schizophrenia compared to controls (104), it could be hypothesized that increasing oxytocin levels improves social cognition in schizophrenia. However, the study of Pedersen et al. (103) has some important limitations. First, the sample size was small. Moreover, they carried out multiple tests in this small sample; therefore the results have to be interpreted with caution. Studies investigating the role of oxytocin in social cognition are sparse. Therefore, to determine the exact role of oxytocin in social cognition more research needs to be conducted on this topic.

In conclusion, the available seven studies suggest preliminary evidence for a role of dopamine, serotonin, and oxytocin in social cognition in schizophrenia patients. GABA does not seem to be a promising target for enhancement of social cognition. However, 
these studies have important limitations. Therefore future research needs to confirm the role of these transmitters in social cognition.

\section{DISCUSSION}

With this review we aimed to provide an outline of the underlying neuropharmacological mechanisms of the separate MATRICS domains. Although some potential targets were identified, overall, results of previous studies attempting to identify potential pharmacological targets for cognitive enhancement have been unsatisfactory. This review has shown that dysfunction in separate cognitive domains seems to arise from different underlying neuropharmacological mechanisms. This suggests that schizophrenia patients with different cognitive impairments could benefit from different (adjunctive) pharmacological agents. The identified potential molecular targets, which include dopamine $\mathrm{D}_{1}$ receptors, serotonin $5-\mathrm{HT}_{1 \mathrm{a}}$ and $5-\mathrm{HT}_{3 \mathrm{a}}$ receptors, nicotinic $\alpha_{7}$ receptors, $\mathrm{GABA}_{\mathrm{A}}$ receptors, and NMDA receptors, are described more extensively below.

\section{DOPAMINE $\mathrm{D}_{\mathbf{1}}$}

Although George et al. (48) were not able to detect positive results with a single dose of $\mathrm{D}_{1}$ agonist dihydrexidine, Pietrzak et al. (72) found improvement in both processing speed and reasoning and problems solving abilities (both aspects of executive functioning) after a single dose of $\mathrm{D}$-amphetamine, an indirect $\mathrm{D}_{1}$ agonist. Decreased dopaminergic neurotransmission in the PFC has been hypothesized to be associated with cognitive dysfunction in schizophrenia (36). Since $\mathrm{D}_{1}$ receptors are highly abundant in the PFC (105), this receptor subtype has been particularly associated with executive function and working memory. A PET study by Okubo et al. (106) found decreased $\mathrm{D}_{1}$ receptors in the PFC in schizophrenia which was indeed associated with poorer executive functioning. Animal studies provide additional evidence for cognitive enhancing effects of $\mathrm{D}_{1}$ receptor agonists as low doses of several $\mathrm{D}_{1}$ agonists were found to enhance cognition in non-human primates $(107,108)$. Because a majority of dopamine receptors in the PFC belong to the $\mathrm{D}_{1}$ subtype, and not to the $\mathrm{D}_{2}$ subtype (109), which is related to psychotic symptom severity, $\mathrm{D}_{1}$ receptors may be a feasible molecular target for enhancement of executive function related aspects of cognition without exacerbation of psychotic symptoms.

\section{SEROTONIN 5-HT ${ }_{1 \mathrm{a}}$ AND 5-HT $3 \mathrm{a}$ RECEPTORS}

(Partial) 5- $\mathrm{HT}_{1 \mathrm{a}}$ receptor agonism was found to improve verbal learning and memory (38-40). These enhancing effects may be due to the high density of $5-\mathrm{HT}_{1 \mathrm{a}}$ receptors in the hippocampus (36), which is an area in the brain well known for its role in memory. In addition, preclinical studies showed that both 5$\mathrm{HT}_{1 \mathrm{a}}$ agonists and antagonist enhanced cognition in rats (110, 111). 5- $\mathrm{HT}_{3 \mathrm{a}}$ receptor antagonism was associated with improvement in visual learning and memory $(43,44)$. Contrary to other subtypes of serotonin receptors, the $5-\mathrm{HT}_{3 \mathrm{a}}$ receptor is the only ligand-gated ion channel subtype (43). To date, not many studies investigated the potential role of $5-\mathrm{HT}_{3 \mathrm{a}}$ receptors in cognition. However, since both Akhondzadeh et al. (43) and Levkovitz et al. (44) found improvement in visual learning and memory with the $5-\mathrm{HT}_{3 \mathrm{a}}$ receptor antagonist ondansetron, these receptors might be a promising molecular target for enhancement of visual learning and memory in schizophrenia.

\section{ACETYLCHOLINE NICOTINIC $\alpha_{7}$ RECEPTORS}

The role of acetylcholine in cognition (particularly in learning, memory, and attention) has been widely established and central dysfunction of the cholinergic system has been found to be associated with cognitive symptoms in neurological diseases as Alzheimer and Parkinson's disease (112-114). However, with the exception of positive results found with nicotine and a partial nicotinic $\alpha_{7}$ agonist on attention $(52,89)$, cholinergic interventions strategies did not affect any of the cognitive domains in the available studies. However, all the available studies that met the inclusion criteria used acetylcholinesterase inhibitors or nicotinic agonists. Although (mostly post-mortem) both nicotinic and muscarinic receptor abnormalities have been repeatedly found in schizophrenia (115-120), nicotinic receptor antagonists do not appear to impair cognition in the same manner as antimuscarinic drugs (121). This might explain the lack of improvement in the described studies. Indeed, a small pilot study by Shekar et al. (122) found that the muscarinic receptor agonist xanomeline improves verbal, visual, and working memory in patients with schizophrenia or schizoaffective disorder. Moreover, xanomeline improved cognition in Alzheimer disease (123). Thus, although positive effects on attention were found with nicotine and a partial nicotinic $\alpha_{7}$ agonist, future studies should focus on muscarinic agents.

\section{GABA $_{\mathbf{A}}$ RECEPTORS}

Both $\mathrm{GABA}_{\mathrm{A}}$ receptor antagonists and agonists were found to affect working memory and verbal learning and memory (35, 80). Multiple studies have shown reduced GABAergic transmission, especially in the PFC, in schizophrenia (124). The PFC is strongly involved in working memory functioning (125) and animal studies have shown that appropriate GABA transmission in the dorsolateral prefrontal cortex (DPFC) is essential to adequate working memory functioning $(36,126)$. Lewis et al. (37) showed that altered GABA transmission in the DPFC is possibly limited to certain cell classes, such as the chandelier cells, which synchronize the activation of the pyramidal neurons via the $\mathrm{GABA}_{\mathrm{A}}$ receptor subtypes. Therefore, $\mathrm{GABA}_{\mathrm{A}}$ receptors may be a promising molecular target for enhancement of working memory.

\section{GLUTAMATE NMDA RECEPTORS}

Glutamate, the primary excitatory neurotransmitter in the mammalian brain, has been linked to learning and memory because of its principal role in modulating long-term potentiation (127), and hyperactivity of glutamatergic neurotransmission has been implicated in schizophrenia (36). It has been hypothesized that cognitive dysfunction in schizophrenia is due to hypofunction of the NMDA receptor (81). Small increases in NMDA-dependent glutamate transmission might enhance cognition, whereas excessive stimulation might have neurodegenerative consequences (36). Activation of the NMDA receptors leads to synthesis of nitric oxide, which is able to further increase the excitotoxicity by increasing glutamate release from presynaptic neurons and inhibition of glial glutamate transporters (73). Indeed, minocycline (which blocks nitric oxide induced neurotoxicity) was found to improve 
visual learning and memory, working memory, and reasoning and problem solving abilities (73). Although D-cycloserine (which non-competitively enhances NMDA neurotransmission) was not found to improve attention and working memory (81), pharmacological agents reducing the neurotoxic effects of extensive glutamate might still be a promising intervention strategy for cognitive enhancement.

\section{CAN THE NEGATIVE RESULTS BE EXPLAINED BY STUDIES LIMITATIONS?}

A substantial number of the studies evaluated in this review addressing pharmacological cognitive enhancement in schizophrenia report negative results. It is debatable whether this is due to ineffectiveness of the agents used, or that potential results were obscured by methodological shortcomings as cognition research in schizophrenia deals with pertinent limitations. First, in many of the studies included in this review, cognition was not the primary outcome parameter. As a result, the design of these studies was not always optimal to measure cognitive enhancement. Second, the sample sizes are often too small to detect clinically relevant effects. Third, concurrent medications may interfere with the investigated pharmacological agents. Patients with schizophrenia are generally treated with antipsychotics. Because the entire mechanism of action of these medications is not completely understood, it cannot be ruled out that antipsychotics alter the effects of the added agents (62). Moreover, patients often use concomitant medications such as benzodiazepines, antidepressants, and anticholinergics, which could influence the effects of the adjunctive pharmacological agents as well. Especially anticholinergic medication is well known for its adverse effects on cognition (29). Therefore, studies including only medication-naïve patients at early stages of the disease are necessary. Fourth, studies often do not use fixed doses. It is possible that certain agents are only effective in a certain dose. If studies do use a fixed dose, this dose is often established for treating the illness or symptoms it was originally used for. However, it is not necessarily so that the same dose is required for cognitive enhancement in schizophrenia. Fifth, research seems to focus on the direct or semi-direct enhancing effect of modulating certain receptors while cognitive decline has most often been a process of a longer period of time possibly implying that enhancement studies should equally allow for more time to yield effects. Also, different paradigms could focus on neuroprotective targets and preventing cognitive decline early in the disorder in contrast to enhancing cognition after impairment. Sixth, not all studies report information about substance use of the participants. Patients with schizophrenia often abuse substances as tobacco, alcohol and cannabis, and epidemiological studies found high co-morbidity rates of substance abuse $(40-60 \%)(128,129)$. Particularly tobacco use can interfere with nicotinic receptor agents as it causes desensitization of this receptor subtype. Although most of the studies excluded patients with a (recent) co-morbid diagnosis of alcohol or drug abuse/dependence, tobacco using patients are almost never excluded. Seventh, studies often use different neuropsychological tasks to measure the same aspects of cognition which makes it difficult to compare the results. Therefore, studies should use a standardized cognitive battery, such as the MATRICS Consensus
Cognitive Battery [MCCB; (84)] or the CANTAB cognitive battery (130). The MCCB in particular, has been composed to reliably assess cognition in schizophrenia patients. At present, only three of the reported studies used this battery to measure cognition $(50,52,59)$. Finally, not all studies used a control group and repeatedly conducted the same test battery without adequately correcting for potential practice effects. Therefore, improvement often cannot be reliably attributed to the effect of the pharmacological agent. Future research should take these limitations in to account in experimental setup and optimize their design for cognition measurement. Ideally, future studies should include a placebo or other control group and should ensure sufficient power by including enough participants. Furthermore, medication-naïve patients should be recruited, preferably non-smokers who do not use other substances as cannabis and alcohol. Regarding the design, future studies should choose cognition as primary outcome measure and optimize the design by using a fixed dose and make sure to choose a dose suitable for schizophrenia patients. Finally, future studies should make sure to choose sufficient trial duration and to use a standardized cognitive test battery which covers all the MATRICS domains. In this manner, studies will be better comparable and the effects of possible confounding variables will be limited. To summarize, the negative results of "pharmacological cognitive enhancement studies" could partially be explained by studies' limitations.

\section{CONCLUSION}

Although some potential targets were identified, overall, results of previous studies attempting to identify potential pharmacological targets for cognitive enhancement have been disappointing. This review has shown that dysfunction in separate cognitive domains may arise from different underlying neuropharmacological mechanisms which suggests that schizophrenia patients with different cognitive impairments could benefit from different intervention strategies. Although development of effective cognitive enhancers is a complex process, it is an exciting challenge for this area of research as improvement of cognition contributes significantly to the quality of life of these patients.

\section{AUTHOR CONTRIBUTIONS}

Wilhelmina A. M. Vingerhoets wrote the first draft of the manuscript. All authors contributed to and have approved the final manuscript.

\section{REFERENCES}

1. Reichenberg A, Weiser M, Caspi A, Knobler HY, Lubin G, Harvey PD, et al. Premorbid intellectual functioning and risk of schizophrenia and spectrum disorders. J Clin Exp Neuropsychol (2006) 28:193-207. doi:10.1080/ 13803390500360372

2. Green MF, Kern RS, Heaton RK. Longitudinal studies of cognition and functional outcome in schizophrenia: implications for MATRICS. Schizophr Res (2004) 72:41-51. doi:10.1016/j.schres.2004.09.009

3. Green MF. What are the functional consequences of neurocognitive deficits in schizophrenia? Am J Psychiatry (1996) 153:321-30.

4. Heinrichs RW. The primacy of cognition in schizophrenia. Am Psychol (2005) 60:229-42. doi:10.1037/0003-066X.60.3.229

5. Burton SC. Strategies for improving adherence to second-generation antipsychotics in patients with schizophrenia by increasing ease of use. J Psychiatr Pract (2005) 11:369-78. doi:10.1097/00131746-200511000-00003 
6. Prouteau A, Verdoux H, Briand C, Lesage A, Lalonde P, Nicole L, et al. Cognitive predictors of psychosocial functioning outcome in schizophrenia: a followup study of subjects participating in a rehabilitation program. Schizophr Res (2005) 77:343-53. doi:10.1016/j.schres.2005.03.001

7. Chen EY, Hui CL, Dunn EL, Miao MY, Yeung WS, Wong CK, et al. A prospective 3-year longitudinal study of cognitive predictors of relapse in first-episode schizophrenic patients. Schizophr Res (2005) 77:99-104. doi:10.1016/j.schres. 2005.02.020

8. National Institute for Health and Clinical Excellence. Schizophrenia: Core Interventions in the Treatment and Management of Schizophrenia in Adults in Primary and Secondary Care (2009). Available from: http://guidance.nice.org.uk/CG82 (Clinical guideline 82).

9. Buchanan RW, Kreyenbuhl J, Kelly DL, Noel JM, Boggs DL, Fischer BA, et al. The 2009 schizophrenia PORT psychopharmacological treatment recommendations and summary statements. Schizophr Bull (2010) 36:71-93. doi:10.1093/schbul/sbp116

10. Hasan A, Falkai P, Wobrock T, Lieberman J, Glenthoj B, Gattaz WF, et al. World Federation of Societies of Biological Psychiatry (WFSBP) guidelines for biological treatment of schizophrenia, part 1: update 2012 on the acute treatment of schizophrenia and the management of treatment resistance. World J Biol Psychiatry (2012) 13:318-78. doi:10.3109/15622975.2012.696143

11. Stip E, Chouinard S, Boulay LJ. On the trail of a cognitive enhancer for the treatment of schizophrenia. Prog Neuropsychopharmacol Biol Psychiatry (2005) 29:219-32. doi:10.1016/j.pnpbp.2004.11.004

12. Volk DW, Lewis DA. Impaired prefrontal inhibition in schizophrenia: relevance for cognitive dysfunction. Physiol Behav (2002) 77:501-5. doi:10.1016/S00319384(02)00936-8

13. Cohen NJ, Ryan J, Hunt C, Romine L, Wszalek T, Nash C. Hippocampal system and declarative (relational) memory: summarizing the data from functional neuroimaging studies. Hippocampus (1999) 9:83-98. doi:10.1002/(SICI)10981063(1999)9:1<83::AID-HIPO9>3.0.CO;2-7

14. Nuechterlein KH, Barch DM, Gold JM, Goldberg TE, Green MF, Heaton RK. Identification of separable cognitive factors in schizophrenia. Schizophr Res (2004) 72:29-39. doi:10.1016/j.schres.2004.09.007

15. Feifel D, Macdonald K, Cobb P, Minassian A. Adjunctive intranasal oxytocin improves verbal memory in people with schizophrenia. Schizophr Res (2012) 139:207-10. doi:10.1016/j.schres.2012.05.018

16. Wagner M, Quednow BB, Westheide J, Schlaepfer TE, Maier W, Kühn KU. Cognitive improvement in schizophrenic patients does not require a serotonergic mechanism: randomized controlled trial of olanzapine vs amisulpride. Neuropsychopharmacology (2005) 30:381-90. doi:10.1038/sj.npp. 1300626

17. Tyson PJ, Roberts KH, Mortimer AM. Are the cognitive effects of atypical antipsychotics influenced by their affinity to 5HT-2A receptors? Int J Neurosci (2004) 114:593-611. doi:10.1080/00207450490430552

18. Keefe RS, Bilder RM, Davis SM, Harvey PD, Palmer BW, Gold JM, et al. Neurocognitive effects of antipsychotic medications in patients with chronic schizophrenia in the CATIE trial. Arch Gen Psychiatry (2007) 64:633-47. doi:10.1001/archpsyc.64.6.633

19. Davidson M, Galderisi S, Weiser M, Werbeloff N, Ph D, Fleischhacker WW, et al. Cognitive effects of antipsychotic drugs in first-episode schizophrenia and schizophreniform disorder: a randomized, open-label clinical trial (EUFEST). Am J Psychiatry (2009) 166:675-82. doi:10.1176/appi.ajp.2008.08060806

20. Purdon SE, Jones BD, Stip E, Labelle A, Addington D, David SR, et al. Neuropsychological change in early phase schizophrenia during 12 months of treatment with olanzapine, risperidone, or haloperidol. Arch Gen Psychiatry (2000) 57:249-58. doi:10.1001/archpsyc.57.3.249

21. Malhotra AK, Burdick KE, Razi K, Bates JA, Sanders M, Kane JM. Ziprasidone-induced cognitive enhancement in schizophrenia: specificity or pseudospecificity? Schizophr Res (2006) 87:181-4. doi:10.1016/j.schres.2006. 05.015

22. Rémillard S, Pourcher E, Cohen H. Long-term effects of risperidone versus haloperidol on verbal memory, attention, and symptomatology in schizophrenia. J Int Neuropsychol Soc (2008) 14:110-8. doi:10.1017/S1355617708080090

23. Harvey PD, Patterson TL, Potter LS, Zhong K, Brecher M. Improvement in social competence with short-term double-blind comparison of quetiapine versus and neuropsychological functioning. Am J Psychiatry (2006) 163:1918-25. doi:10.1176/appi.ajp.163.11.1918
24. Purdon SE, Malla A, Labelle A, Lit W. Neuropsychological change in patients with schizophrenia after treatment with quetiapine or haloperidol. J Psychiatry Neurosci (2001) 26:137-49.

25. Velligan DI, Newcomer J, Pultz J, Csernansky J, Hoff AL, Mahurin R, et al. Does cognitive function improve with quetiapine in comparison to haloperidol? Schizophr Res (2002) 53:239-48. doi:10.1016/S0920-9964(01)00268-7

26. Kivircik Akdede BB, Alptekin K, Kitis A, Arkar H, Akvardar Y. Effects of quetiapine on cognitive functions in schizophrenia. Prog Neuropsychopharmacol Biol Psychiatry (2005) 29:233-8. doi:10.1016/j.pnpbp.2004.11.005

27. Kim S, Shin I, Kim J, Lee S, Lee Y, Yang S, et al. Effects of switching to long-acting injectable risperidone from oral atypical antipsychotics on cognitive function in patients with schizophrenia. Hum Psychopharmacol (2009) 24:565-73. doi:10.1002/hup.1057

28. Suzuki H, Gen K. The influence of switching from haloperidol decanoate depot to risperidone long-acting injection on the clinical symptoms and cognitive function in schizophrenia. Hum Psychopharmacol (2012) 27:470-5. doi:10.1002/hup.2249

29. Campbell N, Boustani M, Limbil T, Ott C, Fox C, Maidment I, et al. The cognitive impact of anticholinergics: a clinical review. Clin Interv Aging (2009) 4:225-33.

30. Surguladze SA, Chu EM, Evans A, Anilkumar AP, Patel MX, Timehin C, et al. The effect of long-acting risperidone on working memory in schizophrenia: a functional magnetic resonance imaging study. J Clin Psychopharmacol (2007) 27:560-70. doi:10.1097/jcp.0b013e31815a256c

31. Kim S-W, Chung Y-C, Lee Y-H, Lee J-H, Kim S-Y, Bae K-Y, et al. Paliperidone ER versus risperidone for neurocognitive function in patients with schizophrenia: a randomized, open-label, controlled trial. Int Clin Psychopharmacol (2012) 27:267-74. doi:10.1097/YIC.0b013e328356acad

32. Purdon SE, Labelle A, Boulay L. Neuropsychological change in schizophrenia after 6 weeks of clozapine. Schizophr Res (2001) 48:57-67. doi:10.1016/S09209964(00)00101-8

33. Ertugrul A, Ucar G, Basar K, Demir B, Yabanoglu S, Ulug B. Influence of clozapine on platelet serotonin, monoamine oxidase and plasma serotonin levels. Psychiatry Res (2007) 149:49-57. doi:10.1016/j.psychres.2005.12.009

34. Sumiyoshi T, Roy A, Kim C-H, Jayathilake K, Lee MA, Sumiyoshi C, et al. Prediction of changes in memory performance by plasma homovanillic acid levels in clozapine-treated patients with schizophrenia. Psychopharmacology (2004) 177:79-83. doi:10.1007/s00213-004-1924-5

35. Geffen Y, Keefe R, Rabinowitz J, Anand R, Davidson M. Bl-1020, a new $\gamma$ aminobutyric acid-enhanced antipsychotic: results of 6-week, randomized, double-blind, controlled, efficacy and safety study. J Clin Psychiatry (2012) 73:1168-74. doi:10.4088/JCP.12m07642

36. Gray JA, Roth BL. Molecular targets for treating cognitive dysfunction in schizophrenia. Schizophr Bull (2007) 33:1100-19. doi:10.1093/schbul/sbm074

37. Lewis DA, Pierri JN, Volk DW, Melchitzky DS, Woo TU. Altered GABA neurotransmission and prefrontal cortical dysfunction in schizophrenia. Biol Psychiatry (1999) 46:616-26. doi:10.1016/S0006-3223(99)00061-X

38. Sumiyoshi T, Matsui M, Yamashita I, Nohara S, Kurachi M, Uehara T, et al. The effect of tandospirone, a serotonin1A agonist, on memory function in schizophrenia. Biol Psychiatry (2001) 49:861-8. doi:10.1016/S0006-3223(00) 01025-8

39. Riedel M, Spellmann I, Schennach-Wolff R, Musil R, Dehning S, Cerovecki A, et al. Effect of aripiprazole on cognition in the treatment of patients with schizophrenia. Pharmacopsychiatry (2010) 43:50-7. doi:10.1055/s-00291239539

40. Bervoets C, Morrens M, Vansteelandt K, Kok F, de Patoul A, Halkin V, et al. Effect of aripiprazole on verbal memory and fluency in schizophrenic patients: results from the ESCAPE study. CNS Drugs (2012) 26:975-82. doi:10.1007/s40263-012-0003-4

41. Suzuki H, Gen K, Inoue Y. An unblinded comparison of the clinical and cognitive effects of switching from first-generation antipsychotics to aripiprazole, perospirone or olanzapine in patients with chronic schizophrenia. Prog Neuropsychopharmacol Biol Psychiatry (2011) 35:161-8. doi:10.1016/j.pnpbp.2010. 10.021

42. Yasui-Furukori N, Kaneda A, Sugawara N, Tomita T, Kaneko S. Effect of adjunctive treatment with aripiprazole to atypical antipsychotics on cognitive function in schizophrenia patients. J Psychopharmacol (2012) 26:806-12. doi:10.1177/0269881111405555 
43. Akhondzadeh S, Mohammadi N, Noroozian M, Karamghadiri N, Ghoreishi A, Jamshidi A-H, et al. Added ondansetron for stable schizophrenia: a double blind, placebo controlled trial. Schizophr Res (2009) 107:206-12. doi:10.1016/j.schres.2008.08.004

44. Levkovitz Y, Arnest G, Mendlovic S, Treves I, Fennig S. The effect of Ondansetron on memory in schizophrenic patients. Brain Res Bull (2005) 65:291-5. doi:10.1016/j.brainresbull.2003.09.022

45. Zhang XY, Liu L, Liu S, Hong X, Chen DC, Xiu MH, et al. Short-term tropisetron treatment and cognitive and P50 auditory gating deficits in schizophrenia. Am J Psychiatry (2012) 169:974-81. doi:10.1176/appi.ajp.2012. 11081289

46. Ishikawa M, Sakata M, Toyohara J, Oda K, Ishii K, Wu J, et al. Occupancy of $\alpha 7$ nicotinic acetylcholine receptors in the brain by tropisetron: a positron emission tomography study using [(11)C]CHIBA-1001 in healthy human subjects. Clin Psychopharmacol Neurosci (2011) 9:111-6. doi:10.9758/cpn.2011.9. 3.111

47. Friedman JI, Ocampo R, Elbaz Z, Parrella M, White L, Bowler S, et al. The effect of citalopram adjunctive treatment added to atypical antipsychotic medications for cognitive performance in patients with schizophrenia. J Clin Psychopharmacol (2005) 25:237-42. doi:10.1097/01.jcp.0000161499. 58266.51

48. George MS, Molnar CE, Grenesko EL, Anderson B, Mu Q, Johnson K, et al. A single $20 \mathrm{mg}$ dose of dihydrexidine (DAR-0100), a full dopamine D1 agonist, is safe and tolerated in patients with schizophrenia. Schizophr Res (2007) 93:42-50. doi:10.1016/j.schres.2007.03.011

49. Karson CN, Mrak RE, Husain MM, Griffin WS. Decreased mesopontine choline acetyltransferase levels in schizophrenia. Mol Chem Neuropathol (1996) 29:181-91. doi:10.1007/BF02815001

50. Tugal O, Yazici KM, Anil Yagcioglu AE, Gögüs A. A double-blind, placebo controlled, cross-over trial of adjunctive donepezil for cognitive impairment in schizophrenia. Int J Neuropsychopharmacol (2004) 7:117-23. doi:10.1017/ S1461145703004024

51. Velligan D, Brenner R, Sicuro F, Walling D, Riesenberg R, Sfera A, et al. Assessment of the effects of AZD3480 on cognitive function in patients with schizophrenia. Schizophr Res (2012) 134:59-64. doi:10.1016/j.schres.2011.10.004

52. Freedman R, Olincy A, Buchanan RW, Harris JG, Gold JM, Johnson L, et al. Initial phase 2 trial of a nicotinic agonist in schizophrenia. Am J Psychiatry (2008) 165:1040-7. doi:10.1176/appi.ajp.2008.07071135

53. Akhondzadeh S, Gerami M, Noroozian M, Karamghadiri N, Ghoreishi A, Abbasi S-H, et al. A 12-week, double-blind, placebo-controlled trial of donepezil adjunctive treatment to risperidone in chronic and stable schizophrenia. Prog Neuropsychopharmacol Biol Psychiatry (2008) 32:1810-5. doi:10. 1016/j.pnpbp.2008.08.001

54. Lee S, Lee J, Lee B, Hoon Y. Galantamine adjunctive treatment to conventional antipsychotics for the cognitive impairments in chronic schizophrenia. Int Clin Psychopharmacol (2007) 22:63-8. doi:10.1097/YIC.0b013e3280117feb

55. Fagerlund B, Søholm B, Fink-Jensen A, Lublin H, Glenthøj BY. Effects of donepezil adjunctive treatment to ziprasidone on cognitive deficits in schizophrenia: a double-blind, placebo-controlled study. Clin Neuropharmacol (2007) 30:3-12. doi:10.1097/01.WNF.0000240940.67241.F6

56. Sharma T, Reed C, Aasen I, Kumari V. Cognitive effects of adjunctive 24-weeks rivastigmine treatment to antipsychotics in schizophrenia: a randomized, placebo-controlled, double-blind investigation. Schizophr Res (2006) 85:73-83. doi:10.1016/j.schres.2006.03.037

57. Freudenreich O, Herz L, Deckersbach T, Evins AE, Henderson DC, Cather C, et al. Added donepezil for stable schizophrenia: a double-blind, placebocontrolled trial. Psychopharmacology (2005) 181:358-63. doi:10.1007/s00213005-2235-1

58. Friedman JI, Adler DN, Howanitz E, Harvey PD, Brenner G, Temporini H, et al. A double blind placebo controlled trial of donepezil adjunctive treatment to risperidone for the cognitive impairment of schizophrenia. Biol Psychiatry (2002) 51:349-57. doi:10.1016/S0006-3223(01)01342-7

59. Buchanan RW, Keefe RS, Lieberman JA, Barch DM, Csernansky JG, Goff DC, et al. A randomized clinical trial of MK-0777 for the treatment of cognitive impairments in people with schizophrenia. Biol Psychiatry (2011) 69:442-9. doi:10.1016/j.biopsych.2010.09.052

60. Friedman JI, Carpenter D, Lu J, Fan J, Tang CY, White L, et al. A pilot study of adjunctive atomoxetine treatment to second-generation antipsychotics for cognitive impairment in schizophrenia. J Clin Psychopharmacol (2008) 28:59-63. doi:10.1097/jcp.0b013e318161318f

61. Kane JM, D'Souza DC, Patkar AA, Youakim JM, Tiller JM, Yang R, et al. Armodafinil as adjunctive therapy in adults with cognitive deficits associated with schizophrenia: a 4-week, double-blind, placebo-controlled study. J Clin Psychiatry (2010) 71:1475-81. doi:10.4088/JCP.09m05950gry

62. Harvey PD. Pharmacological cognitive enhancement in schizophrenia. Neuropsychol Rev (2009) 19:324-35. doi:10.1007/s11065-009-9103-4

63. Turner DC, Clark L, Pomarol-Clotet E, McKenna P, Robbins TW, Sahakian BJ. Modafinil improves cognition and attentional set shifting in patients with chronic schizophrenia. Neuropsychopharmacology (2004) 29:1363-73. doi:10.1038/sj.npp.1300457

64. Ballon JS, Feifel D. A systematic review of modafinil: potential clinical uses and mechanisms of action. J Clin Psychiatry (2006) 67:554-66. doi:10.4088/JCP. v67n0406

65. Kaptsan A, Odessky A, Osher Y, Levine J. Lack of efficacy of 5 grams daily of creatine in schizophrenia: a randomized, double-blind, placebo-controlled trial. J Clin Psychiatry (2007) 68:881-4. doi:10.4088/JCP.v68n0609

66. Gallagher P, Watson S, Smith MS, Ferrier IN, Young AH. Effects of adjunctive mifepristone (RU-486) administration on neurocognitive function and symptoms in schizophrenia. Biol Psychiatry (2005) 57:155-61. doi:10.1016/j. biopsych.2004.10.017

67. Goff DC, Cather C, Freudenreich O, Henderson DC, Evins AE, Culhane MA, et al. A placebo-controlled study of sildenafil effects on cognition in schizophrenia. Psychopharmacology (2009) 202:411-7. doi:10.1007/s00213008-1278-5

68. Stone WS, Seidman LJ, Wojcik JD, Green AI. Glucose effects on cognition in schizophrenia. Schizophr Res (2003) 62:93-103. doi:10.1016/S0920-9964(02) 00406-1

69. Rollnik JD, Borsutzky M, Huber TJ, Mogk H, Seifert J, Emrich HM, et al. Short-term cognitive improvement in schizophrenics treated with typical and atypical neuroleptics. Neuropsychobiology (2002) 45:74-80. doi:10.1159/ 000048680

70. McGurk SR, Green MF, Wirshing WC, Wirshing DA, Marder SR, Mintz J, et al. Antipsychotic and anticholinergic effects on two types of spatial memory in schizophrenia. Schizophr Res (2004) 68:225-33. doi:10.1016/S0920-9964(03) 00123-3

71. Niitsu T, Fujisaki M, Shiina A, Yoshida T, Hasegawa T, Kanahara N, et al. A randomized, double-blind, placebo-controlled trial of fluvoxamine in patients with schizophrenia: a preliminary study. J Clin Psychopharmacol (2012) 32:593-601. doi:10.1097/JCP.0b013e3182664cfc

72. Pietrzak RH, Snyder PJ, Maruff P. Use of an acute challenge with damphetamine to model cognitive improvement in chronic schizophrenia. Hum Psychopharmacol (2010) 25:353-8. doi:10.1002/hup.1118

73. Levkovitz Y, Mendlovich S, Riwkes S, Braw Y, Levkovitch-Verbin H, Gal G, et al. A double-blind, randomized study of minocycline for the treatment of negative and cognitive symptoms in early-phase schizophrenia. J Clin Psychiatry (2010) 71:138-49. doi:10.4088/JCP.08m04666yel

74. Hasselmo ME, Stern CE. Mechanisms underlying working memory for novel information. Trends Cogn Sci (2006) 10:487-93. doi:10.1016/j.tics.2006.09.005

75. Mori K, Nagao M, Yamashita H, Morinobu S, Yamawaki S. Effect of switching to atypical antipsychotics on memory in patients with chronic schizophrenia. Prog Neuropsychopharmacol Biol Psychiatry (2004) 28:659-65. doi:10.1016/j. pnpbp.2004.01.019

76. Papageorgiou C, Oulis P, Vasios C, Kontopantelis E, Uzunoglu N, Rabavilas A, et al. P300 alterations in schizophrenic patients experiencing auditory hallucinations. Eur Neuropsychopharmacol (2004) 14:227-36. doi:10.1016/S0924977X(03)00147-0

77. Nielsen RE, Levander S, Thode D, Nielsen J. Effects of sertindole on cognition in clozapine-treated schizophrenia patients. Acta Psychiatr Scand (2012) 126:31-9. doi:10.1111/j.1600-0447.2012.01840.x

78. Jacobsen LK, D’Souza DC, Mencl WE, Pugh KR, Skudlarski P, Krystal JH. Nicotine effects on brain function and functional connectivity in schizophrenia. Biol Psychiatry (2004) 55:850-8. doi:10.1016/j.biopsych.2003.12.023

79. Rezvani AH, Levin ED. Cognitive effects of nicotine. Biol Psychiatry (2001) 49:258-67. doi:10.1016/S0006-3223(00)01094-5

80. Menzies L, Ooi C, Kamath S, Suckling J, McKenna P, Fletcher P, et al. Effects of $\gamma$-aminobutyric acid-modulating drugs on working memory and brain 
function in patients with schizophrenia. Arch Gen Psychiatry (2007) 64:156-67. doi:10.1001/archpsyc.64.2.156

81. Duncan EJ, Szilagyi S, Schwartz MP, Bugarski-Kirola D, Kunzova A, Negi S, et al. Effects of D-cycloserine on negative symptoms in schizophrenia. Schizophr Res (2004) 71:239-48. doi:10.1016/j.schres.2004.03.013

82. Spence SA, Green RD, Wilkinson ID, Hunter MD. Modafinil modulates anterior cingulate function in chronic schizophrenia. Br J Psychiatry (2005) 187:55-61. doi:10.1192/bjp.187.1.55

83. Luck SJ, Gold JM. The construct of attention in schizophrenia. Biol Psychiatry (2008) 64:34-9. doi:10.1016/j.biopsych.2008.02.014

84. Nuechterlein KH, Green MF, Kern RS, Baade LE, Barch DM, Cohen JD, et al. The MATRICS consensus cognitive battery, part 1: test selection, reliability, and validity. Am J Psychiatry (2008) 165:203-13. doi:10.1176/appi.ajp.2007. 07010042

85. Molina V, Gispert JD, Reig S, Pascau J, Martinez R, Sanz J, et al. Olanzapineinduced cerebral metabolic changes related to symptom improvement in schizophrenia. Pharmacopsychiatry (2003) 20:13-8.

86. Liu SK, Chen WJ, Chang CJ, Lin HN. Effects of atypical neuroleptics on sustained attention deficits in schizophrenia: a trial of risperidone versus haloperidol. Neuropsychopharmacology (2000) 22:311-9. doi:10.1016/S0893-133X(99) 00137-2

87. Golightly KL, Lloyd JA, Hobson JE, Gallagher P, Mercer G, Young AH. Acute tryptophan depletion in schizophrenia. Psychol Med (2001) 31:75-84. doi:10.1017/S0033291799003062

88. Lenzi A, Maltinti E, Poggi E, Fabrizio L, Coli E. Effects of rivastigmine on cognitive function and quality of life in patients with schizophrenia. Clin Neuropharmacol (2003) 26:317-21. doi:10.1097/00002826-200311000-00011

89. Dépatie L, O’Driscoll GA, Holahan AL, Atkinson V, Thavundayil JX, Kin NN, et al. Nicotine and behavioral markers of risk for schizophrenia: a doubleblind, placebo-controlled, cross-over study. Neuropsychopharmacology (2002) 27:1056-70. doi:10.1016/S0893-133X(02)00372-X

90. Knowles EE, David AS, Reichenberg A. Processing speed deficits in schizophrenia: reexamining the evidence. Am J Psychiatry (2010) 167:828-35. doi:10.1176/appi.ajp.2010.09070937

91. Strous RD, Stryjer R, Maayan R, Gal G, Viglin D, Katz E, et al. Analysis of clinical symptomatology, extrapyramidal symptoms and neurocognitive dysfunction following dehydroepiandrosterone (DHEA) administration in olanzapine treated schizophrenia patients: a randomized, double-blind placebo controlled trial. Psychoneuroendocrinology (2007) 32:96-105. doi:10.1016/j. psyneuen.2006.11.002

92. Muscatello MR, Bruno A, Pandolfo G, Micò U, Bellinghieri PM, Scimeca G, et al. Topiramate augmentation of clozapine in schizophrenia: a double-blind, placebo-controlled study. J Psychopharmacol (2011) 25:667-74. doi:10.1177/ 0269881110372548

93. Zoccali R, Muscatello M, Bruno A, Cambria R. The effect of lamotrigine augmentation of clozapine in a sample of treatment-resistant schizophrenic patients: a double-blind, placebo-controlled study. Schizophr Res (2007) 93:109-16. doi:10.1016/j.schres.2007.02.009

94. Kalyoncu A, Mirsal H, Pektas O, Unsalan N, Tan D, Beyazyürek M. Use of lamotrigine to augment clozapine in patients with resistant schizophrenia and comorbid alcohol dependence: a potent anti-craving effect? J Psychopharmacol (2005) 19:301-5. doi:10.1177/0269881105051542

95. Beer JS, Ochsner KN. Social cognition: a multi level analysis. Brain Res (2006) 1079:98-105. doi:10.1016/j.brainres.2006.01.002

96. Adolphs R. The neurobiology of social cognition. Curr Opin Neurobiol (2001) 11:231-9. doi:10.1016/S0959-4388(00)00202-6

97. Mizrahi R, Korostil M, Starkstein SE, Zipursky RB, Kapur S. The effect of antipsychotic treatment on theory of mind. Psychol Med (2007) 37:595-601. doi:10.1017/S0033291706009342

98. Burns MJ. The pharmacology and toxicology of atypical antipsychotic agents. Clin Toxicol (2001) 39:1-14.

99. Singh AN, Barlas C, Saeedi H, Mishra RK. Effect of loxapine on peripheral dopamine-like and serotonin receptors in patients with schizophrenia. J Psychiatry Neurosci (2003) 28:39-47.

100. Sumiyoshi T, Higuchi Y, Itoh T, Matsui M, Arai H, Suzuki M. Effect of perospirone on P300 electrophysiological activity and social cognition in schizophrenia: a three-dimensional analysis with sloreta. Psychiatry Res (2009) 172:180-3. doi:10.1016/j.pscychresns.2008.07.005
101. Behere RV, Venkatasubramanian G, Arasappa R, Reddy N, Gangadhar BN. Effect of risperidone on emotion recognition deficits in antipsychotic-naïve schizophrenia: a short-term follow-up study. Schizophr Res (2009) 113:72-6. doi:10.1016/j.schres.2009.05.026

102. Kosfeld M, Heinrichs M, Zak PJ, Fischbacher U, Fehr E. Oxytocin increases trust in humans. Nature (2005) 435:673-6. doi:10.1038/nature03701

103. Pedersen CA, Gibson CM, Rau SW, Salimi K, Smedley KL, Casey RL, et al. Intranasal oxytocin reduces psychotic symptoms and improves theory of mind and social perception in schizophrenia. Schizophr Res (2011) 132:50-3. doi:10.1016/j.schres.2011.07.027

104. Kéri S, Kiss I, Kelemen O. Sharing secrets: oxytocin and trust in schizophrenia. Soc Neurosci (2009) 4:287-93. doi:10.1080/17470910802319710

105. Takahashi H, Yamada M, Suhara T. Functional significance of central D1 receptors in cognition: beyond working memory. J Cereb Blood Flow Metab (2012) 32:1248-58. doi:10.1038/jcbfm.2011.194

106. Okubo Y, Suhara T, Suzuki K, Kobayashi K, Inoue O, Terasaki O, et al. Decreased prefrontal dopamine D1 receptors in schizophrenia revealed by PET. Nature (1997) 385:634-6. doi:10.1038/385634a0

107. Cai JX, Arnsten AF. Dose-dependent effects of the dopamine D1 receptor agonists A77636 or SKF81297 on spatial working memory in aged monkeys. JPharmacol Exp Ther (1997) 283:183-9.

108. Arnsten AF, Cai JX, Murphy BL, Goldman-Rakic PS. Dopamine D1 receptor mechanisms in the cognitive performance of young adult and aged monkeys. Psychopharmacology (1994) 116:143-51. doi:10.1007/BF02245056

109. Galletly C. Recent advances in treating cognitive impairment in schizophrenia. Psychopharmacology (2009) 202:259-73. doi:10.1007/s00213-008-1302-9

110. Winstanley CA, Chudasama Y, Dalley JW, Theobald DE, Glennon JC, Robbins TW. Intra-prefrontal 8-OH-DPAT and M100907 improve visuospatial attention and decrease impulsivity on the five-choice serial reaction time task in rats. Psychopharmacology (2003) 167:304-14. doi:10.1007/s00213-003-1398-x

111. Boast C, Bartolomeo AC, Morris H, Moyer JA. 5HT antagonists attenuate MK801-impaired radial arm maze performance in rats. Neurobiol Learn Mem (1999) 71:259-71. doi:10.1006/nlme.1998.3886

112. Van der Zee EA, Platt B, Riedel G. Acetylcholine: future research and perspectives. Behav Brain Res (2011) 221:583-6. doi:10.1016/j.bbr.2011.01.050

113. Lieberman JA, Javitch JA, Moore H. Cholinergic agonists as novel treatments for schizophrenia: the promise of rational. Am J Psychiatry (2008) 165:931-6. doi:10.1176/appi.ajp.2008.08050769

114. Friedman JI. Cholinergic targets for cognitive enhancement in schizophrenia: focus on cholinesterase inhibitors and muscarinic agonists. Psychopharmacology (2004) 174:45-53. doi:10.1007/s00213-004-1794-x

115. Raedler TJ, Knable MB, Jones DW, Urbina RA, Gorey JG, Lee KS, et al. In vivo determination of muscarinic acetylcholine receptor availability in schizophrenia. Am J Psychiatry (2003) 160:118-27. doi:10.1176/appi.ajp.160.1.118

116. Crook JM, Tomaskovic-Crook E, Copolov DL, Dean B. Low muscarinic receptor binding in prefrontal cortex from subjects with schizophrenia: a study of Brodmann's areas $8,9,10$, and 46 and the effects of neuroleptic drug treatment. Am J Psychiatry (2001) 158:918-25. doi:10.1176/appi.ajp.158.987.918

117. Crook JM, Tomaskovic-Crook E, Copolov DL, Dean B. Decreased muscarinic receptor binding in subjects with schizophrenia: a study of the human hippocampal formation. Biol Psychiatry (2000) 48:381-8. doi:10.1016/S00063223(00)00918-5

118. Breese CR, Lee MJ, Adams CE, Sullivan B, Logel J, Gillen KM, et al. Abnormal regulation of high affinity nicotinic receptors in subjects with schizophrenia. Neuropsychopharmacology (2000) 23:351-64. doi:10.1016/S0893$133 \mathrm{X}(00) 00121-4$

119. Dean B, Crook J, Opeskin K, Hill C, Keks N, Copolov D. The density of muscarinic M1 receptors is decreased in the caudate-putamen of subjects with schizophrenia. Mol Psychiatry (1996) 1:54-8.

120. Freedman R, Hall M, Adler LE, Leonard S. Evidence in postmortem brain tissue for decreased numbers of hippocampal nicotinic receptors in schizophrenia. Biol Psychiatry (1995) 38:22-33. doi:10.1016/0006-3223(94)00252-X

121. Everitt BJ, Robbins TW. Central cholinergic systems and cognition. Annu Rev Psychol (1997) 48:649-84. doi:10.1146/annurev.psych.48.1.649

122. Shekhar A, Potter WZ, Lightfoot J, Lienemann J, Dubé S, Mallinckrodt C, et al. Selective muscarinic receptor agonist xanomeline as a novel treatment approach for schizophrenia. Am J Psychiatry (2008) 165:1033-9. doi:10.1176/ appi.ajp.2008.06091591 
123. Bodick NC, Offen WW, Levey AI, Cutler NR, Gauthier SG, Satlin A, et al. Effects of xanomeline, a selective muscarinic receptor agonist, on cognitive function and behavioral symptoms in Alzheimer disease. Arch Neurol (1997) 54:465-73. doi:10.1001/archneur.1997.00550160091022

124. Blum BP, Mann JJ. The GABAergic system in schizophrenia. Int J Neuropsychopharmacol (2002) 5:159-79. doi:10.1017/S1461145702002894

125. Kane MJ, Engle RW. The role of prefrontal cortex in working-memory capacity, executive attention, and general fluid intelligence: an individual-differences perspective. Psychon Bull Rev (2002) 9:637-71.

126. Lewis DA, Volk DW, Hashimoto T. Selective alterations in prefrontal cortical GABA neurotransmission in schizophrenia: a novel target for the treatment of working memory dysfunction. Psychopharmacology (2004) 174:143-50. doi:10.1007/s00213-003-1673-x

127. Javitt DC. Glutamate as a therapeutic target in psychiatric disorders. Mol Psychiatry (2004) 9:984-97. doi:10.1038/sj.mp.4001551

128. Malchow B, Hasan A, Fusar-Poli P, Schmitt A, Falkai P, Wobrock T. Cannabis abuse and brain morphology in schizophrenia: a review of the available evidence. Eur Arch Psychiatry Clin Neurosci (2013) 263:3-13. doi:10.1007/ s00406-012-0346-3

129. Lubman DI, King JA, Castle DJ. Treating comorbid substance use disorders in schizophrenia. Int Rev Psychiatry (2010) 22:191-201. doi:10.3109/ 09540261003689958
130. Levaux M-N, Potvin S, Sepehry AA, Sablier J, Mendrek A, Stip E. Computerized assessment of cognition in schizophrenia: promises and pitfalls of CANTAB. Eur Psychiatry (2007) 22:104-15. doi:10.1016/j.eurpsy.2006.11.004

Conflict of Interest Statement: The authors declare that the research was conducted in the absence of any commercial or financial relationships that could be construed as a potential conflict of interest.

Received: 01 August 2013; accepted: 16 November 2013; published online: 04 December 2013.

Citation: Vingerhoets WAM, Bloemen OJN, Bakker G and van Amelsvoort TAMJ (2013) Pharmacological interventions for the MATRICS cognitive domains in schizophrenia: what's the evidence? Front. Psychiatry 4:157. doi: 10.3389/fpsyt.2013.00157 This article was submitted to Schizophrenia, a section of the journal Frontiers in Psychiatry.

Copyright (c) 2013 Vingerhoets, Bloemen, Bakker and van Amelsvoort. This is an openaccess article distributed under the terms of the Creative Commons Attribution License (CC BY). The use, distribution or reproduction in other forums is permitted, provided the original author(s) or licensor are credited and that the original publication in this journal is cited, in accordance with accepted academic practice. No use, distribution or reproduction is permitted which does not comply with these terms. 